\title{
Ab Initio Calculations of Material Properties for Modeling Debris: FY 2021 Progress Report
}

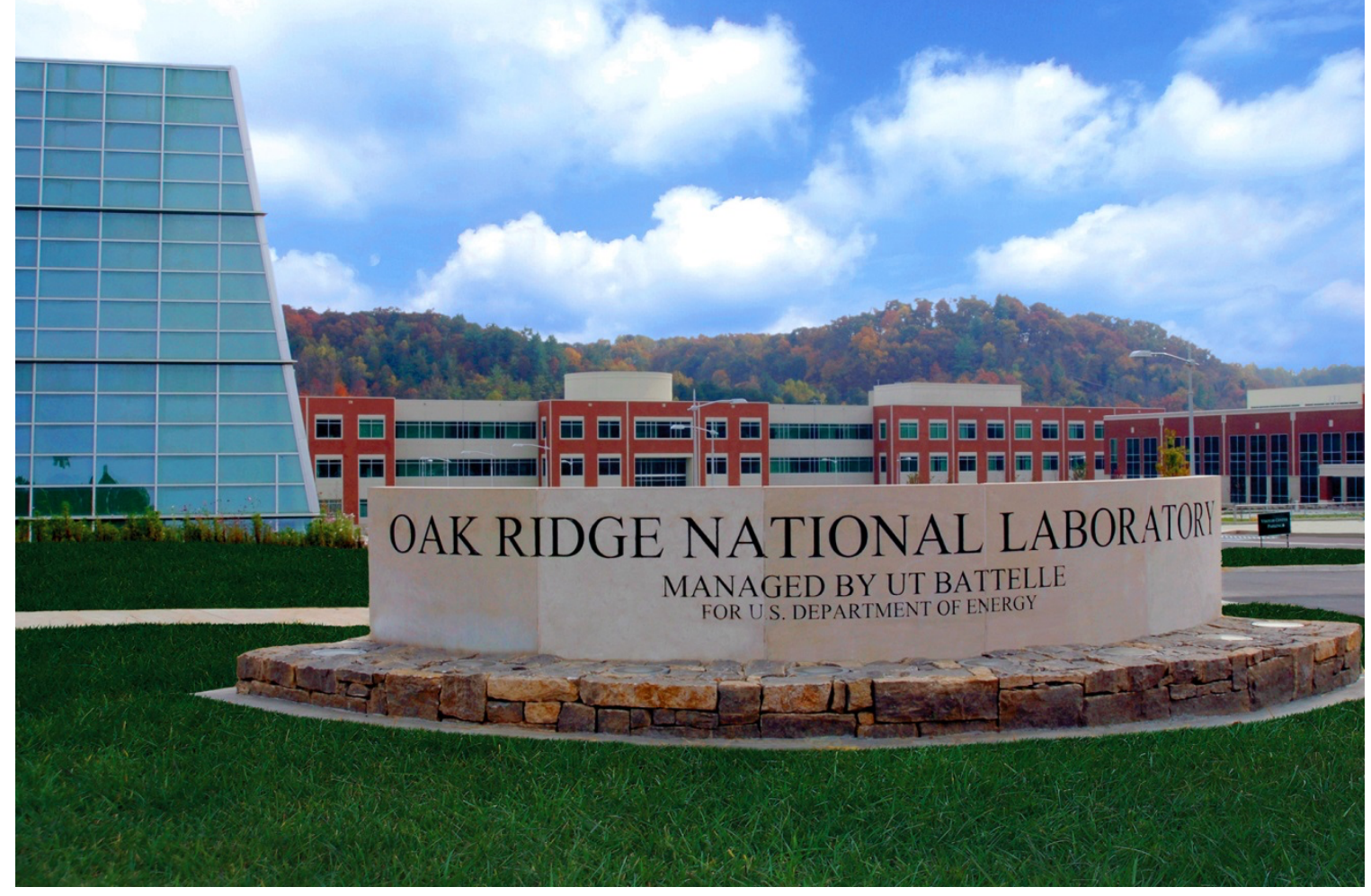

David Abrecht

Pablo Moresco

Erik Nykwest

Ashley Shields

September 2021 


\section{DOCUMENT AVAILABILITY}

Reports produced after January 1, 1996, are generally available free via US Department of Energy (DOE) SciTech Connect.

Website www.osti.gov

Reports produced before January 1, 1996, may be purchased by members of the public from the following source:

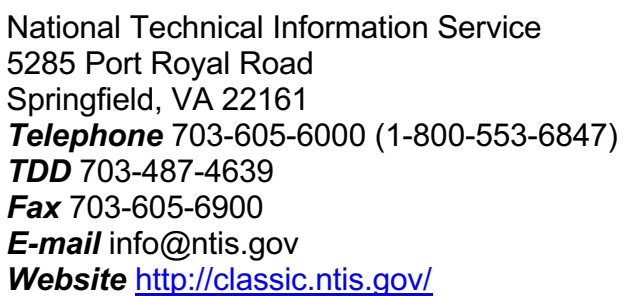

Reports are available to DOE employees, DOE contractors, Energy Technology Data Exchange representatives, and International Nuclear Information System representatives from the following source:

Office of Scientific and Technical Information

PO Box 62

Oak Ridge, TN 37831

Telephone 865-576-8401

Fax 865-576-5728

E-mail reports@osti.gov

Website https://www.osti.gov/

This report was prepared as an account of work sponsored by an agency of the United States Government. Neither the United States Government nor any agency thereof, nor any of their employees, makes any warranty, express or implied, or assumes any legal liability or responsibility for the accuracy, completeness, or usefulness of any information, apparatus, product, or process disclosed, or represents that its use would not infringe privately owned rights. Reference herein to any specific commercial product, process, or service by trade name, trademark, manufacturer, or otherwise, does not necessarily constitute or imply its endorsement, recommendation, or favoring by the United States Government or any agency thereof. The views and opinions of authors expressed herein do not necessarily state or reflect those of the United States Government or any agency thereof. 
National Security Sciences Directorate

Nuclear Nonproliferation Division

\title{
AB INITIO CALCULATIONS OF MATERIAL PROPERTIES FOR MODELING DEBRIS:
} FY 2021 PROGRESS REPORT

\author{
David Abrecht \\ Pablo Moresco \\ Erik Nykwest \\ Ashley Shields
}

September 2021

Prepared by

OAK RIDGE NATIONAL LABORATORY

Oak Ridge, TN 37831-6283

managed by

UT-BATTELLE LLC

for the

US DEPARTMENT OF ENERGY

under contract DE-AC05-00OR22725 



\section{CONTENTS}

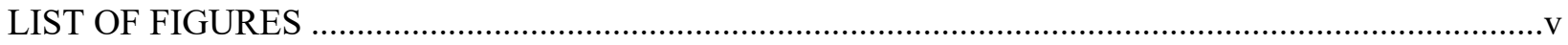

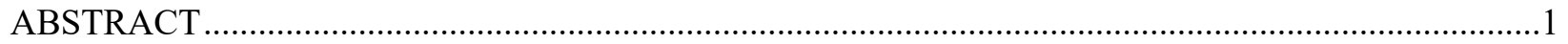

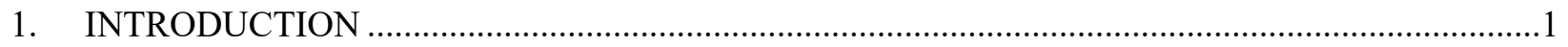

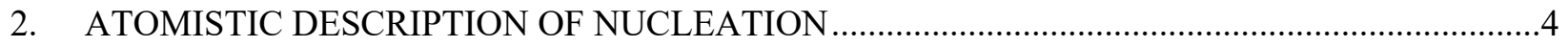

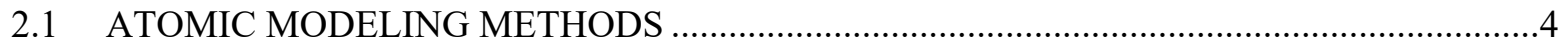

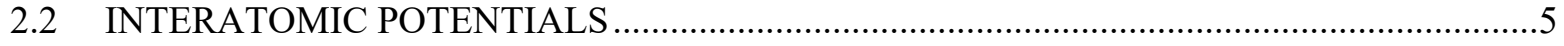

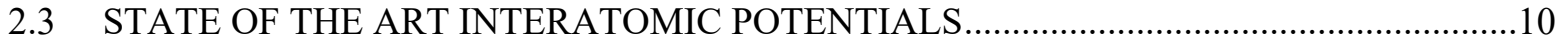

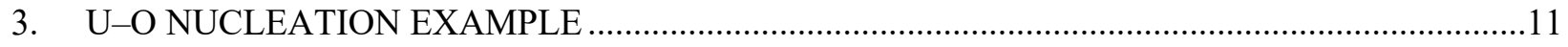

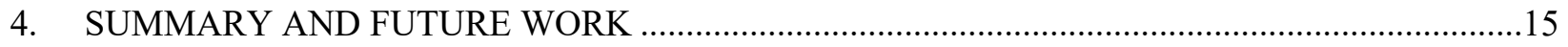

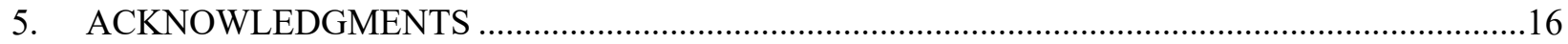

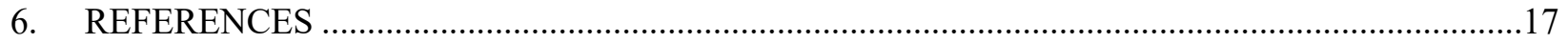

APPENDIX A. Thermodynamic parameters for the U-O system …................................................... A-1

APPENDIX B. Kinetic reaction coefficients for the U-O system ....................................................... 



\section{LIST OF FIGURES}

Figure 1. Schematic of the variation of Gibbs free energy with cluster size during homogenous nucleation.

Figure 2. Calculated lattice constants, $\mathrm{L}$, of fcc $\mathrm{UO}_{2}$ vs. temperature, as predicted by $\mathrm{MD}$ simulations using various potentials.

Figure 3. Evolution of Young's polycrystalline moduli as a function temperature and plutonium content calculated with Arima-05 (blues), Boyarchenkov-07 (greens), and Cooper-14 (reds) potentials compared with the IAEA reference data, adapted from Balboa[36]

Figure 4. Lattice parameter of $\mathrm{UO}_{2}$ predicted by the updated Cooper potential compared to

Figure 5. Comparison of the $\mathrm{UO}_{2}$ thermal conductivity obtained from MD simulations and

experiments.

Figure 6 . The $\mathrm{E}_{\text {for }} / \mathrm{O}$ (square) and $\mathrm{E}_{\text {for }} / \mathrm{U}$ (circle) of all relaxed oxide structures across the whole range of $\mathrm{O} / \mathrm{U}$ ratio.

Figure 7. Chemical evolution of species with time as the test system evolved. 11

Figure 8 . Temperature history and particle count per $\mathrm{m}^{3}$ for the simulated chemistry..... .14 15 



\begin{abstract}
This report summarizes the work done during the first 6 months of the project " $A b$ initio calculations of material properties for modeling debris" that is part of the Rapid Response Research $\left(R^{3}\right)$ Venture. The main focus for this fiscal year (FY) has been the evaluation of classical interatomic potentials for the description of the condensation of uranium oxides in the regimes relevant to fireball conditions. We also delineate how these functions will be used within the molecular dynamics and Monte Carlo frameworks to compute thermodynamic properties of these materials. These descriptions are to be utilized within continuum modeling formulations to generate a more accurate characterization of the homogeneous nucleation process.
\end{abstract}

\title{
1. INTRODUCTION
}

The capability to predict the characteristics and trajectories of debris particles formed after a nuclear burst plays an important role in the planning of emergency response and forensic analysis activities [1]. In particular, having information on the particle size distribution of the debris population and the variation of nuclide mass ratios among samples taken at different locations is fundamental for planning debris collection operations and can support the debris diagnostic work [2], [3].

The early temperatures in the nuclear fireball are high enough for the weapon components and fission products, as well as some of the structures in the proximity of the burst, to be vaporized [4]. As the fireball cools down by thermal radiation and entrainment of cooler air from the environment, those vapors become supersaturated, and a condensed phase appears by homogeneous nucleation, which subsequently acts as a substrate for further condensation to occur. Depending on the characteristics of the weapon emplacement, additional masses can be driven into the fireball by the response of surrounding structures to thermal and blast effects, which can also become part of the debris evolution [5].

A complicating aspect in developing an understanding of the formation of nuclear debris is the limited availability of experimental measurements of the relevant processes and material properties. Information about debris properties are currently based on samples from the aboveground nuclear tests [6]. The rather narrow range of conditions in which those tests were carried out suggests that the observed characteristics may not be representative of the parameter space of interest to nuclear forensics.

Reproducing the conditions of the nuclear fireball in the laboratory has been challenging so far. Experimental work using radioactive materials can be intrinsically hazardous and expensive. Although some progress has been made by studying plasmas formed by laser ablation and inductive coupling, important aspects of the debris evolution such as the cooling time scales have not been adequately captured [7], [8]. On the other hand, a full description of the debris condensation process at the quantum level is beyond the state-of-the-art computational capabilities, and current modeling efforts are focused on classical thermodynamic formalisms, which use statistical mechanics approaches to obtain macroscopic descriptions of the processes at the atomic scale [9]. This reduction in the number of degrees of freedom involves several physical assumptions and contains parameters, such as chemical reaction rates, that need to be determined experimentally or using higher fidelity models.

In this project we look at employing several approximations to the atomistic description of matter to complement macroscopic models of debris formation currently under development. Initially we are focusing on improving the description of the homogeneous nucleation process for the conditions relevant to the nuclear fireball. By homogeneous nucleation we refer to the formation of a condensed phase from the vapor mix in the gas. Since this involves the appearance of an interface, there is an associated energy barrier that needs to be surmounted and usually requires substantial levels of supersaturation [10]. 
The classical theory of nucleation uses macroscopic quantities to describe the properties of the condensed phase, such as representing the interface energy by means of the surface tension of the substance. It also treats the growth of clusters as occurring one molecule at a time, while ignoring the depletion of the gas phase [11]. In this theory, the molecular clusters are deemed to be spherical with radius $r$, containing $n$ molecules and satisfy

$$
n=\frac{4 \pi}{3} \frac{r^{3} \rho_{c}}{\bar{m}}
$$

where $\rho_{c}$ is the density of the condensed phase and $\bar{m}$ is the average molecular weight. The Gibbs free energy of formation of a cluster with $n$ molecules can then be written

$$
\Delta G=\left(g_{c}-g_{g}\right) \frac{4 \pi r^{3} \rho_{c}}{3 \bar{m}}+4 \pi r^{2} \sigma=\left(g_{c}-g_{g}\right) n+\sigma(4 \pi)^{1 / 3}\left(\frac{3 \bar{m} n}{\rho_{c}}\right)^{2 / 3},
$$

where $\sigma$ is the surface tension of the condensing substance and $g_{c}$ and $g_{g}$ are the Gibbs free energy per molecule in the condensed and gas phases, respectively. Thus, the two terms on the right-hand side represent the bulk and surface contribution to the free energy of the cluster, and the former can be related to the supersaturation of the gas phase, $\Sigma$, by

$$
g_{c}-g_{g}=-k_{B} T_{g} \ln \Sigma,
$$

where $T_{g}$ is the temperature of the gas and $k_{B}$ is Boltzmann constant [11]. Under supersaturation conditions, the bulk and surface term will have opposite signs, and their combination results in the formation of an energy barrier (Figure 1). The maximum of the energy barrier delimits clusters that are stable and unstable (i.e., those that will tend to grow or evaporate), and the critical radius, $r^{*}$, can be obtained as

$$
r^{*}=\frac{2 \sigma}{k_{B} T_{g} \ln \Sigma} \frac{\bar{m}}{\rho_{c}}
$$

or equivalently, by defining $n^{*}$ as the critical number of molecules in a stable cluster,

$$
n^{*}=\sigma^{3} \frac{32}{3} \pi\left(\frac{\bar{m}}{\rho_{c}}\right)^{2} \frac{1}{\left(k_{B} T_{g} \ln \Sigma\right)^{3}} .
$$

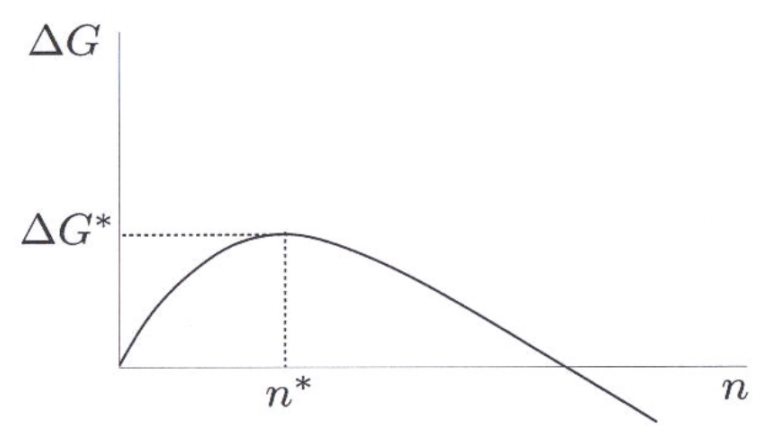

Figure 1. Schematic of the variation of Gibbs free energy with cluster size during homogeneous nucleation. 
The classical theory then provides a simple expression for the nucleation rate, $J$, which is the number of stable clusters formed per unit time and volume:

$$
J=X \exp \left(-\frac{\Delta G\left(n^{*}\right)}{k_{B} T_{g}}\right),
$$

with $X$ corresponding to the collision rate of a cluster of the critical size with molecules in the gas [11].

This description is very economical from a computational point of view, but the predicted nucleation rates have been found to differ by several orders of magnitude from those measured experimentally [12]. The root of this discrepancy has been associated with inaccuracies in the description of the cluster population and collision rates, as well as the use of macroscopic properties to describe the free energy of nanometersized clusters [10]. In the case of the nuclear fireball and its relatively high cooling rates, the fast evolution of the system renders the assumptions of the classical nucleation theory especially questionable. As part of this work, we will employ well-established approximations to the full quantum mechanical descriptions of atomic interactions to better characterize the nucleation process for the conditions and compositions relevant to the fireball. Initially we will focus on uranium oxide systems because they can be one of the most abundant components in the debris particles and thus can play an important role in determining properties such as the size distribution of the population.

In recent decades, research on descriptions of nucleation at the atomic scale have focused on formulations based on kinetic process, in which clusters of different sizes "react" according to rates that depend on their sizes and temperature [13]. Most of these works have adopted the assumption that interactions occur only among clusters and monomers and hence satisfy kinetic equations of the form

$$
\frac{d N_{i}}{d t}=k_{i-1}^{+} N_{i-1}-k_{i}^{-} N_{i}-k_{i}^{+} N_{i}+k_{i+1}^{-} N_{i+1}
$$

where $N_{i}$ is the number of clusters of size $i$ and $t$ is time. Within this framework, several theories have been put forward that derive expressions for the reaction rate constants, $k^{+}$and $k^{-}$, and the associated equilibrium cluster distribution, under different assumptions. Using molecular kinetics, it is then possible to relate those quantities to thermodynamic functions, such as the Gibbs free energy, which can then be used within the classical theory of nucleation, providing an improvement on the original formulation without substantially increasing the computational cost of the models [11].

Computing the statistical mechanical properties of the cluster populations requires calculation of ensemble averages in phase space. To accomplish this, the two main techniques that have been used are molecular dynamics [14] and Monte Carlo approaches [15], which each have advantages depending on the characteristics of the system. In both cases, functions of intermolecular potential energy need to be computed either within a quantum mechanics formalism or by means of classical potential functions.

Although the approaches enumerated above assume the system to be in a quasi-steady state, current stateof-the-art computers allow for the study of nucleation processes dynamically when using classical interatomic potentials. Nucleation events at realistic levels of supersaturation are rare, but it is now possible to consider systems large enough and compute their evolution for long enough time, such that a sufficient number of nucleation clusters are formed and a statistical analysis is possible, allowing for the determination of critical nuclei sizes and nucleation rates [16]. Although computationally more costly, the dynamic approach has the advantage of relying on fewer assumptions than the descriptions based on kinetic formalism, and hence it reduces the uncertainty when evaluating the validity of our models. This is especially important in our case because the regimes relevant to the nuclear fireball have not been widely considered before. 
During the first part of this project, we focused on evaluating the classical potential functions describing uranium oxides that are best suited to the conditions of the fireball for which these species would condense by homogeneous nucleation. A review of the literature and the criteria employed are discussed in Section 2. We also evaluated the modifications that will be required to model the microphysics of debris formation, currently under development by Moresco [9], to incorporate the functional descriptions obtained at the atomistic approaches (Section 3).

\section{ATOMISTIC DESCRIPTION OF NUCLEATION}

\subsection{ATOMIC MODELING METHODS}

$\mathrm{Ab}$ initio electronic structure calculations including density functional theory (DFT) provide an accurate description of fundamental chemical properties but are computationally expensive. Continued advances in high-performance computing (HPC) make DFT calculations more tractable, even on systems with hundreds of atoms. However, there are some well-known limitations to DFT in both theory and practice. DFT is a ground-state theory, requiring further approximations to incorporate temperature effects or calculate the electronic structure of excited states. Practically, the computational cost of DFT increases nonlinearly with the number of atoms and the number of electrons in the simulations, making heavy elements - like those present in the fireball - particularly costly to model. DFT simulations are typically performed on dozens or hundreds of atoms, not the thousands of atoms necessary to observe nucleation events in a system. At the atomic level, nucleation is a low probability event in a gas-phase system. To capture the atomic interactions leading to nucleation requires the exploration of a large phase space, with many possible energy states. Where DFT shines is in the accurate calculation of the energies of formation of small systems and the interaction (binding) energies between atoms or at interfaces.

Molecular dynamics (MD) is a commonly used method for investigating complex chemical reactions at the length and time scales of interest to debris nucleation. MD simulations attempt to predict the motion of individual atoms or molecules in a system as a function of time. At the start of an MD simulation, the exact position of the atoms and molecules are specified by the user; the forces between the atoms or molecules are then calculated, and finally the position of the atoms are stepped forward in time by an incremental amount using Newton's laws of motion. This process of calculating forces and updating atom positions is then repeated until the reaction of interest is completed or enough data has been collected to draw a statistical conclusion.

Force calculation in MD simulations comes in two flavors: classical molecular dynamics (CMD), and quantum molecular dynamics (QMD). QMD uses ab initio electronic structure calculations that do not rely on experimental measurements to determine forces (as such, it is also often referred to as ab initio molecular dynamics). QMD methods treat electrons as quantum objects that obey fundamental laws of physics, such as Schrodinger's equation, and are highly accurate but computationally intensive, typically limiting simulations to fewer than 100 atoms $\left(\sim 1 \mathrm{~nm}^{3}, \sim 0.5 \mathrm{ps}\right)$. CMD methods, alternatively, treat atoms and molecules as classical objects (such as hard spheres or ridged rotors) that interact with each other according to user-defined classical potentials or force fields. CMD methods run much faster than QMD methods, which allows for much larger simulations $\left(\sim 5 \mathrm{~nm}^{3}\right)$ with longer time scales $(\sim 50 \mathrm{ps})$, but they are highly sensitive to the user's choice of force field. CMD methods are most useful when studying thermodynamic properties that can be interpreted via statistics. In other words, CMD is most effective when the exact motion of the atoms is not as important as their collective behavior.

Monte Carlo methods have also been applied to the study of nucleation reactions and, like MD, come in quantum (QMC) and classical flavors. MC methods most broadly refer to optimization algorithms based on random sampling and can take many forms. For nucleation, the emphasis is on calculating and minimizing the Gibbs free energy of a system as atoms come together to form particles. Monte Carlo 
methods optimize the energy of the simulation system via a random sampling of available states along a Boltzmann distribution, allowing for the incorporation of temperature effects in these models.

Applications of MC methods to nucleation simulations have primarily focused on nucleating clusters and nanoparticles and can bridge length and time scales from atomistic MD to continuum models [15], [17].

However, MC methods can also be applied to the smaller, atom-level length scales representative of early fireball conditions. As with classical $\mathrm{MD}, \mathrm{MC}$ simulations require extensive parameterization to describe interactions between the species present in the simulation box. For nucleation from the gas phase, the same classical interatomic potentials can be used for both MD and MC to calculate the Gibbs free energy of the system.

\subsection{INTERATOMIC POTENTIALS}

Classical potentials (or force fields) are empirical or semiempirical functions that predict the force or bond energy between two or more atoms. Most force fields take on a flexible functional form, such as those shown in Equations (8)-(11), whose force or energy predictions may be adjusted by changing the values of the parameters. Many styles of classical potentials exist, but all of them rely on some form of fitting to find an optimum set of values for physical parameters so that MD simulations can reproduce specific experimental measurements, such as thermal expansion and elastic properties. Alternatively, classical potentials may be fit to predictions from higher level theories, such as electronic structure methods like DFT. An example potential is given below. In this example, Equation (8) gives the energy of an individual atom $i$ and the total energy of the system as the sum over all the individual atom energies, $E_{i} \cdot[18]$

$$
E_{i}=E C_{i}+E B_{i}+E M_{i}
$$

Equation (8) has three contributions to the total energy, a Coulombic term $\left(E C_{i}\right)$, a Buckingham term $\left(E B_{i}\right)$, and a Morse term $\left(E M_{i}\right)$, which are defined in Equation (9)-(11).

$$
\begin{gathered}
E C_{i}=\frac{1}{2} \sum_{j} \frac{q_{i} q_{j}}{4 \pi \varepsilon_{0} r_{i j}} \\
E B_{i}=\frac{1}{2} \sum_{j} A_{i j} \exp \left(-\frac{r_{i j}}{\rho_{i j}}\right)-\frac{C_{i j}}{r_{i j}^{6}} \\
E M_{i}=\frac{1}{2} \sum_{j} D_{i j}\left\{\left[\exp \left(-\beta_{i j}\left(r-r_{i j}^{*}\right)\right)-1\right]^{2}-1\right\},
\end{gathered}
$$

where $r_{i j}$ is the distance between atoms $i$ and $j, q$ is the charge on the atom, $\varepsilon_{0}$ is the vacuum permittivity, and the other variables $A, \rho, C, D$, and $\beta$, are the adjustable parameters.

Parameterizing classical force fields requires significant effort because potentials are not transferable between elemental species, and small changes in the parameters may lead to large changes in the predicted properties. A specific CMD potential may provide an excellent prediction of a property that was considered during the fitting process (e.g., thermal expansion), within the specific temperature and pressure range (e.g., 300-600 K), but it may provide erroneous results outside of that pressure and temperature range (e.g., $800 \mathrm{~K}$ ) or when used to predict properties not included in the fitting process (e.g., elastic properties, or relative phase stability). Accordingly, CMD potentials must be rigorously tested before their predictions can be trusted. 
To establish an understanding of the current state of classical potentials for uranium-oxygen systems, a literature search has been conducted and the suitability of 14 classical interatomic potentials to model a nuclear event have been evaluated. When drawing conclusions about the relative performance between potentials, we first rely on the conclusions of cited authors who have conducted direct comparisons within a single publication. If direct comparisons between two potentials are not available, then we try to create an indirect comparison with additional literature (similar to the using transitive property in mathematics). Each potential is referred to by the first author's last name and publication date. To maintain compatibility with referenced sources, some potentials have a second name listed in parathesis.

The following are the 14 interatomic potentials evaluated with the naming convention described above:

- Walker-81 [19]

- Yamada-00 [20]

- Basak-03 [21]

- Busker-03(02) [22]

- Morelon-03 [23]

- Arima-05 [24]

- Boyarchenkov-07 [25] (MOX-07)
- Kupryazhkin-08 [26] (Nekrasov-08)

- Goel-08 [27]

- Yakub-09 [28]

- Tiwary-11 [29]

- Cooper-14 [30]

- Li-19 [31]

- Mbongo-20 [32]

Because of the intense heat and explosive power of nuclear weapons, the remnants of the weapon and fission products are expected to initially be in gas form, whereas materials entrained into the fireball will be partially vaporized. Accordingly, it is important for MD and MC models of debris formation to use interatomic potentials that accurately reproduce the chemical and physical properties of the gas phase. Previous parameterization work has focused primarily on the prediction of, or validation against, experimental or DFT-calculated material properties of solid fluorite $\mathrm{UO}_{2}$. No peer-reviewed literature was found that validated the performance of these potentials against the gas phase, and any work regarding the liquid phase primarily focused on prediction of the melting point.

Several review articles already exist comparing the performance of many of the potentials. The most comprehensive comparison of potentials for mixed oxide fuels (MOX) was published by Potashnikov et al. in 2011 [33], where they review 10 different uranium-oxygen potentials (before Potashnikov, publications by Govers et al. [34], [35] were the most comprehensive, reviewing over 20 potentials). For each potential, they run large scale simulations (1,500 atoms) on the face-centered cubic (fcc) fluorite structure of $\mathrm{UO}_{2}$ and calculate the lattice constant, thermal expansion, bulk modulus, heat capacity, and enthalpy as a function of temperature up to the melting point. The potentials they reviewed were Walker81, Yamada-00, Basak-03, Busker-03, Morelon-03, Kupryazhkin-08, Goel-08, Arima-05, Boyarchenkov07 (MOX-07), and Yakub-09. After a thorough analysis of the results, they conclude the best predictions are demonstrated by Yakub-09, and their very own potential Boyarchenkov-07, which they refer to as MOX-07.

Figure 2 summarizes how the tested potentials perform across a range of temperatures with respect to predicting the lattice constant. The dotted line represents the International Atomic Energy Agency (IAEA) reference data for thermal expansion. Some potentials (Busker-03) start to deviate from the experimental reference starting as low as $900 \mathrm{~K}$. However, the Yakub-09 predictions lie directly on top of the recommended curve all the way up to 2,300 K, while MOX-07 predictions match all the way up to 2,700 K. Above 2,700 K Yakub-09 and MOX-07 still give the most accurate predictions. While the predictions are not perfect, this pattern of superior performance compared to the other potentials is repeated across both enthalpy, which is used to predict phase stability, and heat capacity, which depends heavily on phonons and interatomic forces. Based on this evaluation, Yakub-09 and MOX-07 are serviceable force fields for the simulation of a broad range of physical and chemical characteristics in $\mathrm{UO}_{2}$ and were used as the baseline for evaluating potentials published later than 2011 . 


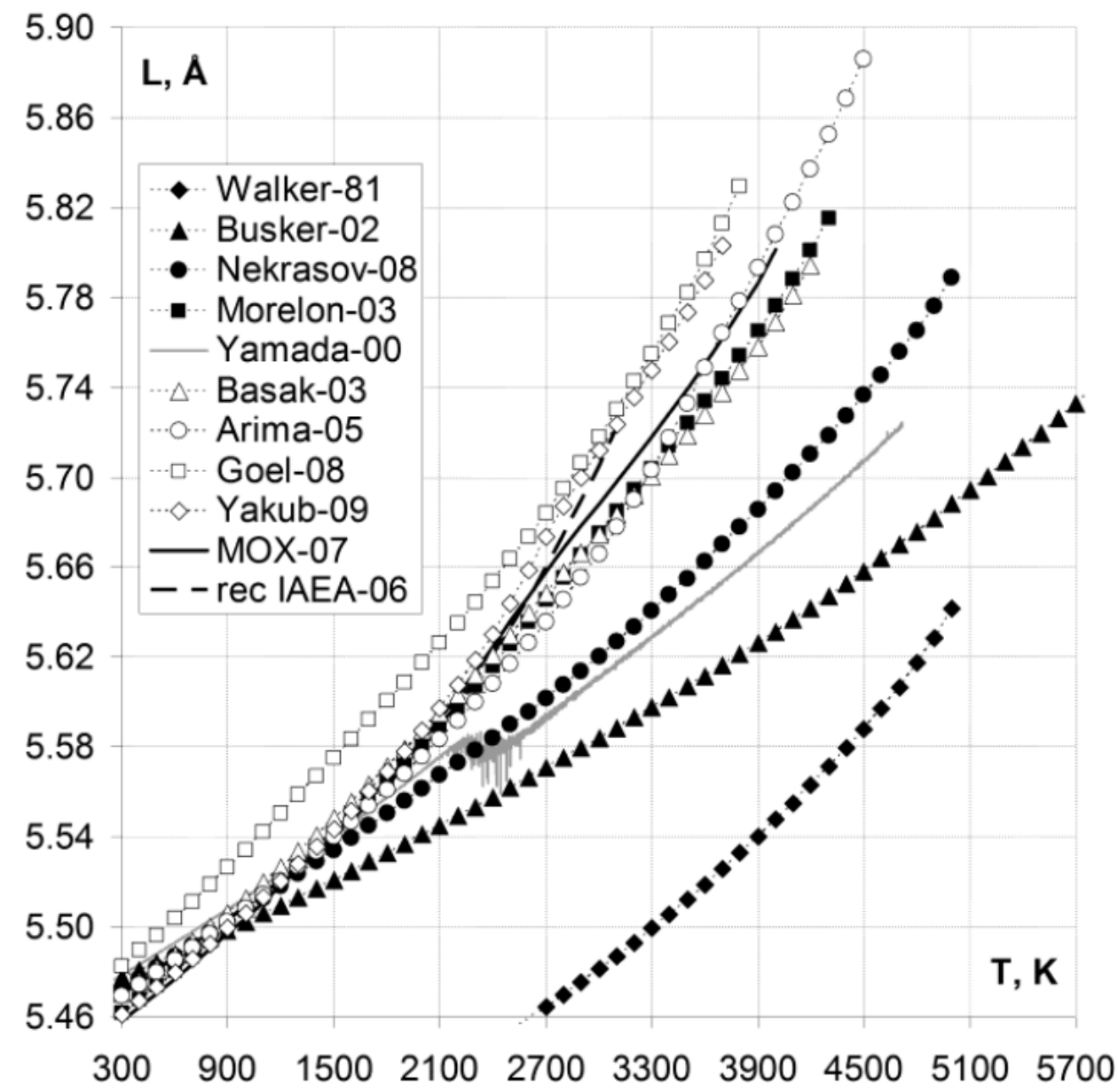

Figure 2. Calculated lattice constants, $\mathrm{L}$, of fcc $\mathrm{UO}_{2}$ vs. temperature, as predicted by MD simulations using various potentials. Experimental reference data is represented by the dashed black line. Reproduced from Potashnikov [33].

More recently, Balboa, Van Brutzel, Chartier, and Le Bouar published a comparison of the performance of $\mathrm{U}_{1-\mathrm{y}} \mathrm{Pu}_{\mathrm{y}} \mathrm{O}_{2}$ mixed oxide potentials in 2017 [36] focusing on the Yamada-00, Arima-05, MOX-07, Tiwary-11, and Cooper-14 potentials. The authors performed molecular dynamics simulations on $7 \times 7 \times$ 7 supercells of $\mathrm{U}_{1-\mathrm{y}} \mathrm{Pu}_{\mathrm{y}} \mathrm{O}_{2}$ in the fluorite structure, generating more than 4,000 atoms in the simulation cell, between $300 \mathrm{~K}$ and the melting point. They then compared the predicted values for the lattice constants, thermal expansion, specific heat, elastic constants, stress/strain curves, and crack propagation for each of the potentials. The authors almost immediately discarded the Tiwary-11 potential because it does not provide a stable fluorite structure. The authors additionally discarded the Yamada- 00 potential because the predicted lattice constants show a large discrepancy with experimental values and, contrary to experimental data, the $\mathrm{PuO}_{2}$ structure underwent a spontaneous phase transformation from the facecentered cubic fluorite unit cell to a tetragonal, rutile-like structure. After completing the remaining tests (thermal expansion, specific heat, elastic constants), the authors concluded the best agreement was obtained with the MOX-7 and Cooper-14 potentials. In addition, the Cooper-14 potential produced the most accurate predictions of the elastic constants. Figure 33 shows the predicted Young's moduli of polycrystalline $\mathrm{U}_{1-\mathrm{y}} \mathrm{Pu}_{\mathrm{y}} \mathrm{O}_{2}$ over a range of temperatures. Across the entire span of temperatures, the Cooper-14 potential agreed well with experiments, but MOX-07 systematically underestimated the experimental values and Arima-05 systematically overestimated the experimental values. 


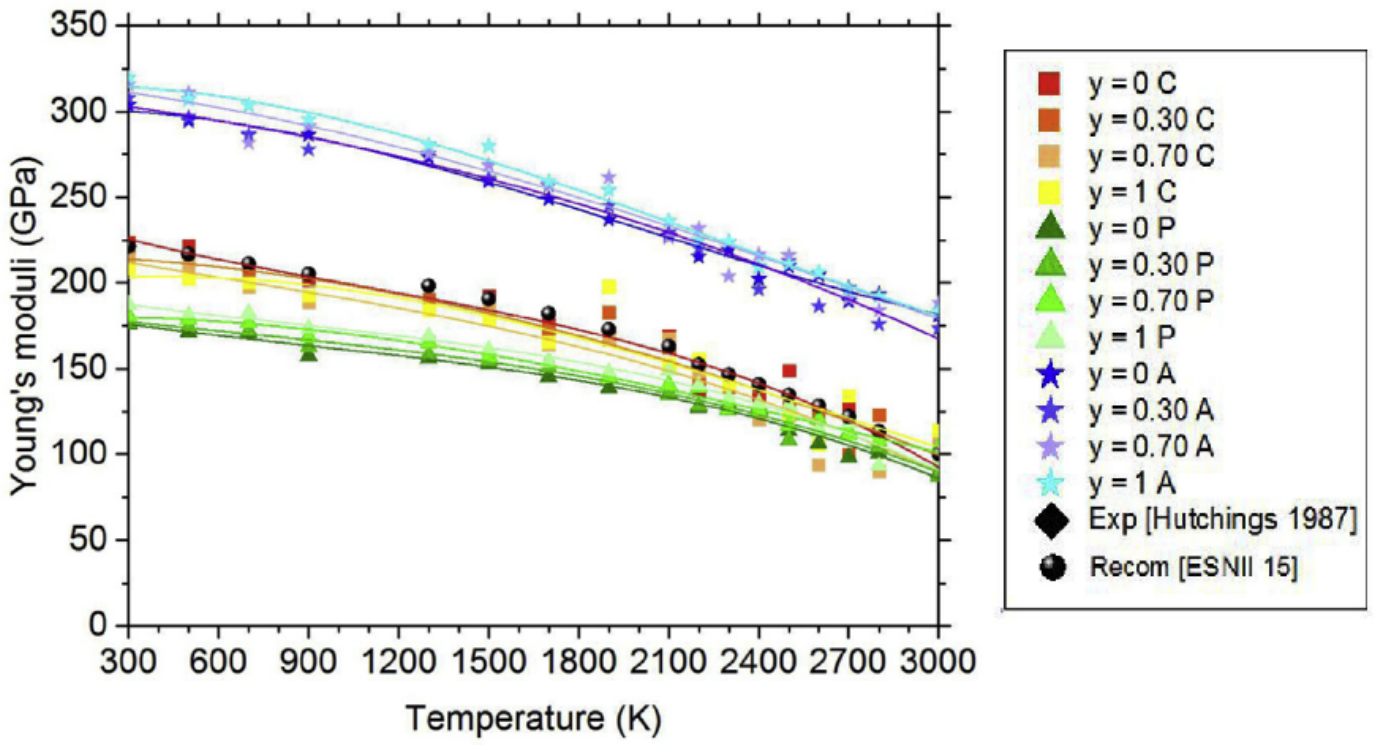

Figure 3. Evolution of Young's polycrystalline moduli as a function of temperature and plutonium content calculated with Arima-05 (blues), Boyarchenkov-07 (greens), and Cooper-14 (reds) potentials compared with

the IAEA reference data, adapted from Balboa [36]. The chemical space examined was $\mathrm{U}_{1-y} \mathrm{Pu}_{\mathrm{y}} \mathrm{O}_{2}$ for $\boldsymbol{y}=$ $[0,0.3,0.7,1]$. Dark colors represent high $\mathrm{U}$ content (low Pu), and light colors represent low U content (high Pu).

Based on their potential forms, a direct sequence of improvement can be drawn between the Yamada-00, Basak-03, Yakub-09, and Cooper-14 potentials. Yamada et al. [20] appears to be the first to apply a partially ionic Busing-Ida type potential [37], shown earlier in Equation (8), to $\mathrm{UO}_{2}$. Basak et al. [21] improved on Yamada's potential by fitting the potential to experimental thermal expansion data across a wider temperature range (300-3,000 K vs 300-1,600 K) than Yamada. Yakub et al. [28], [38] improved the parameters yet again by implementing a self-consistent iterative fitting procedure, running many simulations with many different parameters to search for the set that most accurately reproduced the experimental density from 300 to 3,100 K. Finally, Cooper et al. [30] added an embedded atom component into the potential, shown below in Equation (12), which further improved the accuracy, especially for predictions of the elastic moduli as discussed earlier.

$$
E A M_{i}=-G_{i} \sqrt{\sum_{j}\left(\frac{\eta_{j}}{r_{i j}^{8}}\right)\left(\frac{\left\{1+\operatorname{erf}\left[20\left(r_{i j}-1.5\right)\right]\right\}}{2}\right)}
$$

Since the Cooper-14 potential can be understood as a direct improvement on the Yakub-09 potential, and because of their similar performance, any comparisons with the MOX-07 potential can safely be assumed to also be true for the Yakub-09 potential. Therefore, based on the body of literature sampled, we conclude that of all the uranium-oxygen potentials considered that were published before 2017, the Cooper potential was the most accurate across a large variety of properties. The most recent update to the potential was published in 2016 [39], where the authors parameterize a uranium ${ }^{+5}$-oxygen interatomic potential that agrees well with experimental changes in the lattice parameter (see Figure 4), as well as the thermal conductivity (see Figure 5) above $800 \mathrm{~K}$, for hyperstoichiometric $\mathrm{UO}_{2+\mathrm{x}}$, but yields a distorted oxygen sublattice for $\mathrm{U}_{4} \mathrm{O}_{9}$. 


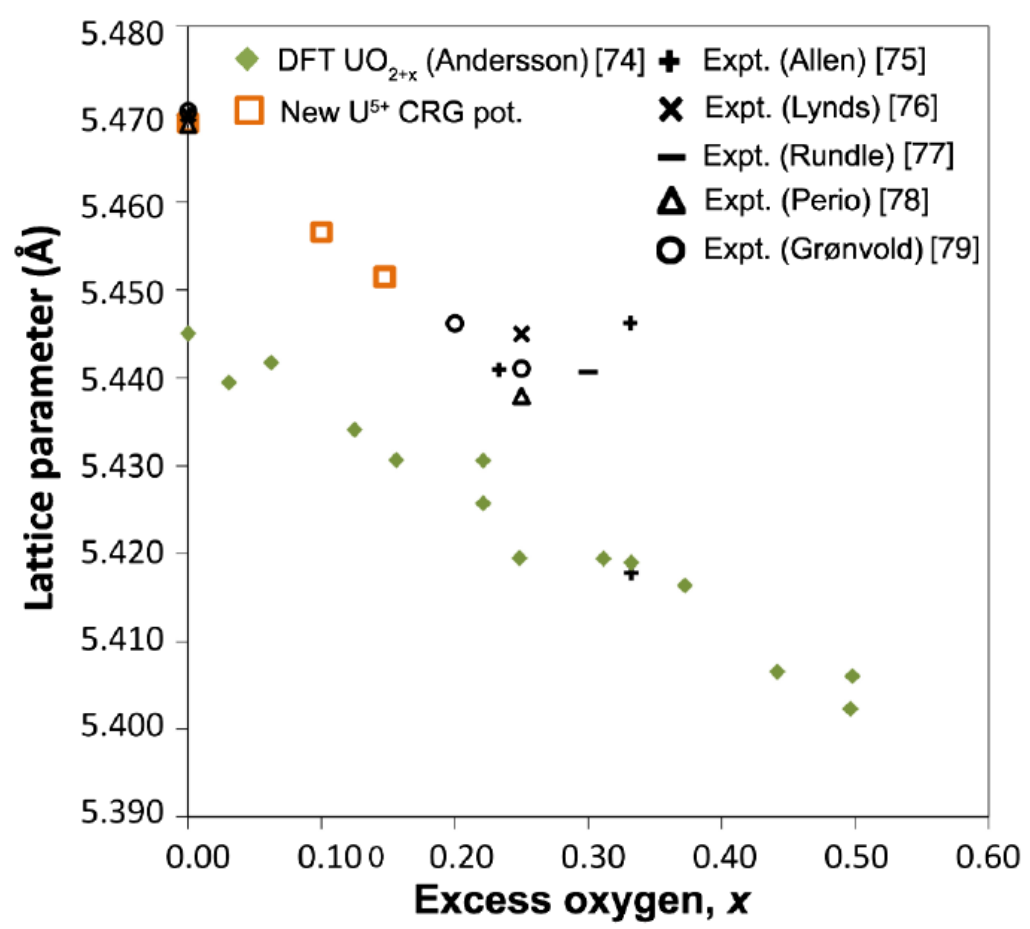

Figure 4. Lattice parameter of $\mathrm{UO}_{2}$ predicted by the updated Cooper potential compared to experimental values and DFT. Reproduced from Liu et al. [40]. DFT values are shown as green diamonds, their CMD predictions are shown as orange squares, and experimental values are shown in black.

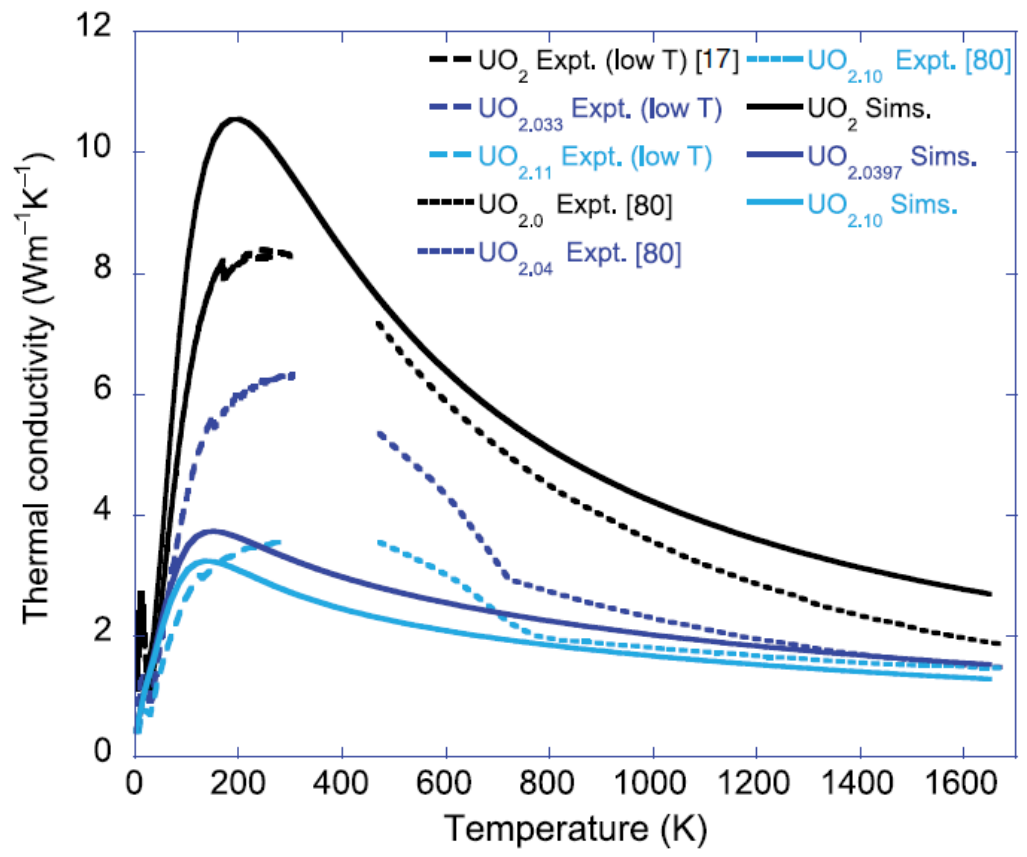

Figure 5. Comparison of the $\mathrm{UO}_{2}$ thermal conductivity obtained from MD simulations and experiments. Reproduced from Liu et al. [40]. Experimental values are shown as dotted lines, and simulation values are shown as solid lines. 


\subsection{STATE OF THE ART INTERATOMIC POTENTIALS}

The newest potentials investigated are a charge-optimized many body (COMB) potential by Li [31] published in 2019 and an improved second-moment tight-binding variable-charge (SMTB-Q) interatomic potential by Mbongo et al. [32] published in 2020. Since they are so new, little is known about the performance of these potentials beyond what is reported in the original publications. Starting with the most recent potential, Mbongo modified the traditional SMTB-Q model by introducing crystal field splitting of the uranium $5 \mathrm{f}$ orbitals. Accordingly, this potential produces excellent predictions for the fluorite phase it is intended to model. It exactly reproduced the experimental cohesive energy and lattice constant, predicted the bandgap to within $0.1 \mathrm{eV}$ (within the reported experimental error), and predicted the bulk modulus to within $1 \mathrm{GPa}(+0.5 \%$ error over the experimental value). However, because crystal field splitting is a function of the local coordination environment, it may not provide accurate simulations for any other solid, liquid, or amorphous phase. This concern is supported by cohesive energy calculations for cotunnite, scrutinyite, and rutile phases of UO presented in the paper that show discrepancies as large as $0.35 \mathrm{eV} / \mathrm{f}$.u. when compared to DFT, which is not precise enough to determine the correct energetic ordering of the phases. Therefore, it is not suitable for modeling nucleation, condensation, or related processes that involve many different coordination environments. If further improvements were made such that the crystal field splitting could adapt to the local coordination environment, then this potential may provide excellent predictions.

Li claims their COMB potential can model all the major uranium oxides $\left(\mathrm{U}_{\mathrm{x}} \mathrm{O}_{\mathrm{y}}\right)$, including $\mathrm{UO}, \mathrm{UO}_{2}$, $\mathrm{UO}_{3}, \mathrm{U}_{2} \mathrm{O}_{5}, \mathrm{U}_{3} \mathrm{O}_{7}, \mathrm{U}_{3} \mathrm{O}_{8}, \mathrm{U}_{4} \mathrm{O}_{9}$, and their various phases. Li performed molecular dynamics simulations on various uranium-oxygen systems using a simulation cell approximately $50 \times 50 \times 50 \AA^{3}$ in size and compared the predicted properties (such as cohesive energy, formation energy, lattice constants, elastic moduli, etc.) with other MD potentials, DFT, and experimental results where available. The agreement of some parameters is very good, but other predicted properties, such as the heat of fusion, are only in fair agreement with DFT and experiment. The Li-19 potential appears to be able to reproduce the relative energy differences between different $\mathrm{U}_{\mathrm{x}} \mathrm{O}_{\mathrm{y}}$ compositions and phases with a higher level of accuracy than older potentials, such as Yakub-09 and Arima-05. Figure 6, reproduced from the original publication of Li [31], shows the excellent agreement with DFT and experimental values for the Li-19-calculated formation energy per uranium atom $\left(\mathrm{E}_{\text {for }} / \mathrm{U}\right)$ and per oxygen atom $\left(\mathrm{E}_{\mathrm{for}} / \mathrm{O}\right)$ for various stoichiometries.

Unfortunately, these results require further validation because the manuscript did not clearly describe how the formation energies were calculated. The earliest version of this COMB potential, first published in 2013 [41], also highlights that solid-state performance was the primary goal in the development of this force field, so liquid phase accuracy was sacrificed for increased bulk phase accuracy. Finally, COMB style potentials are expected to be computationally more expensive than embedded atom method (EAM) potentials by two to three orders of magnitude [42], limiting the time and length scales that can be modeled. 


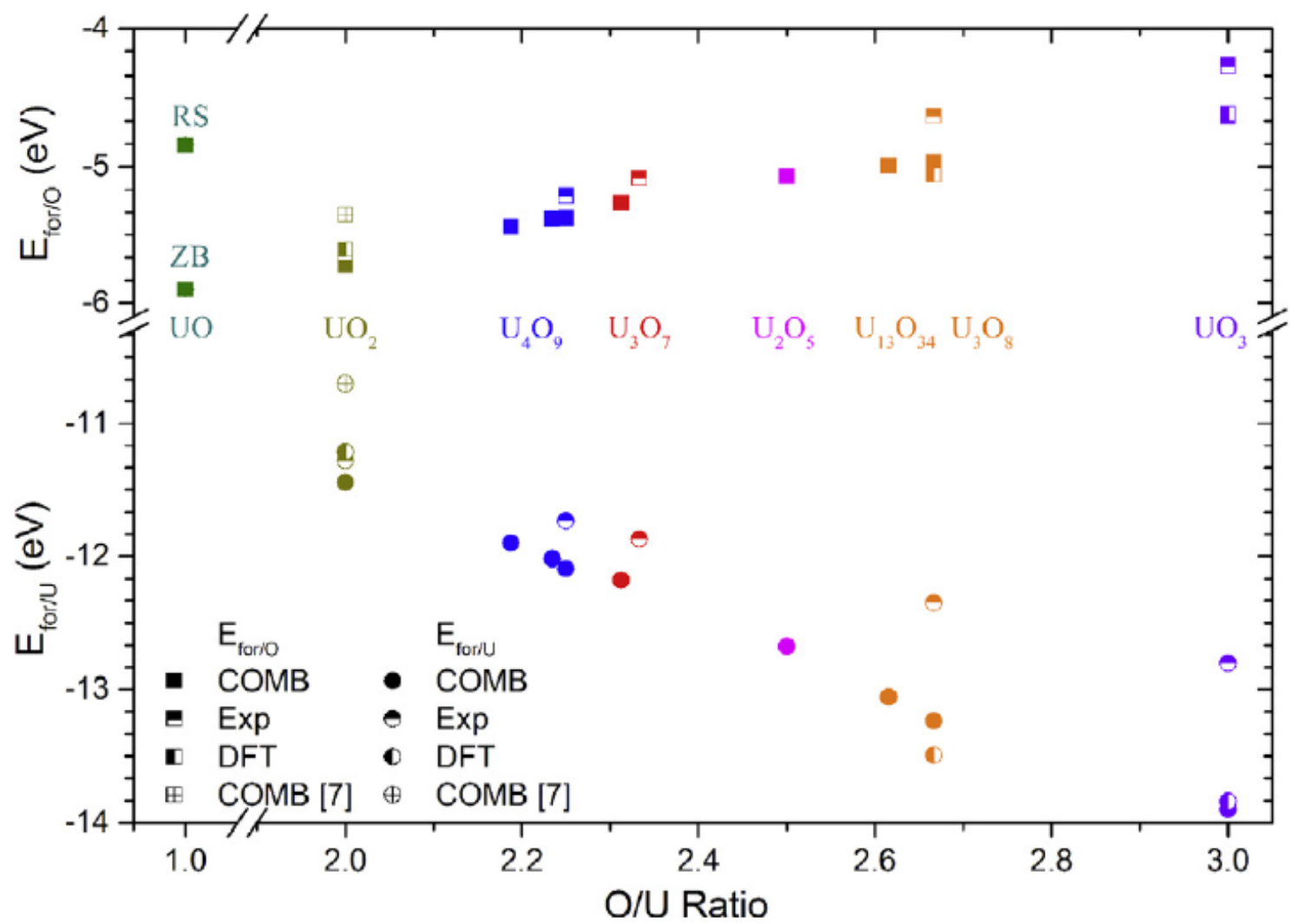

Figure 6. The $E_{\text {for }} / O$ (square) and $E_{\text {for }} / U$ (circle) of all relaxed oxide structures across the whole range of $O / U$ ratio. Solid symbols represent the current COMB potential while partially filled symbols represent DFT (horizontal fill) or experiment (vertical fill). The COMB [7] predictions are based on an older parameterization of the potential.

Figure reproduced from $\mathrm{Li}[31]$.

\section{U-O NUCLEATION EXAMPLE}

To appropriately address the nucleation of uranium oxide particulates, the gas phase chemical speciation must be understood and paired with the solid phase behavior obtained from molecular scale calculations. To accomplish this and to provide a framework for assessing the impact of the assessed molecular scale properties at the macroscopic scale, we have developed a scheme for performing bulk scale chemical kinetics calculations of gas phase uranium-oxygen species.

The current framework used a research debris microphysics code currently in development, based on the models described previously [9] and coupled to a solver of the chemical kinetics equations based on the method by Gear [43]. To treat the high temperature and cooling behavior of the individual chemical species, the code was modified to allow a description of the gas phase heat capacity by means of a userdefined function, enabling the use of NASA polynomials [44] to describe the thermodynamic functions of individual uranium oxide species.

The current investigation looks at nine gas phase chemical species $\left(\mathrm{O}, \mathrm{O}_{2}, \mathrm{O}_{3}, \mathrm{U}, \mathrm{UO}, \mathrm{UO}_{2}, \mathrm{UO}_{3}, \mathrm{U}_{2} \mathrm{O}_{3}\right.$, $\mathrm{U}_{2} \mathrm{O}_{2}$ ) and their relationship to condensed $\mathrm{U}$ and $\mathrm{UO}_{2}$ described, for now, by classical nucleation theory. Thermodynamic properties for the heat capacity of $\mathrm{O}, \mathrm{O}_{2}, \mathrm{O}_{3}, \mathrm{U}, \mathrm{UO}, \mathrm{UO}_{2}$, and $\mathrm{UO}_{3}$ are reasonably well established and have been included in several reference publications [45]-[47]. The thermodynamic properties of $\mathrm{U}_{2} \mathrm{O}_{3}$ and $\mathrm{U}_{2} \mathrm{O}_{2}$ are less well known because these species generally constitute only a very 
small fraction of the gas phase composition in the uranium-oxygen system [48] and have not been extensively studied. We have included values for these species available from the literature [49]. The list of the values used and the references for their use appear in APPENDIX A.

To implement the chemical kinetics for the transformation between gas species, we use a selection of the chemical kinetic equations described by Finko for the system [50]. This set of chemical kinetic equations heavily assumes the mechanism of the uranium-oxygen transformations parallels the aluminum-oxygen system and fits constants to the uranium transformations accordingly. Although this approximation is valid using the currently available experimental data, we anticipate that further experimental work will require these assumptions to be re-examined.

For this work, we have chosen a subset of the equations that does not include ionic or excited state interactions. The formation of particulate is expected to be in a temperature regime where the gas phase is electrically neutral and below the electronic excitation states of the oxygen species listed in the full set.

Examining the implementation of the research debris code, there are some inconsistencies in the treatment of the physics that had to be addressed and are worth noting here. Kinetic equations in the code are treated as solely following the Arrhenius format, where the kinetic rate constant, $k$, is given by

$$
k=A T^{-n} e^{-\frac{E}{R T}}
$$

with $A$ and $n$ being fitted prefactor and exponents with appropriate units, $E$ being an activation energy (cal mol ${ }^{-1}$ ), $R$ being the gas constant $\left(\approx 1.987 \mathrm{cal} \mathrm{mol}^{-1} \mathrm{~K}^{-1}\right)$, and $T$ being the temperature $(\mathrm{K})$. However, limiting the chemical kinetic equations to the Arrhenius form is inconsistent with complex descriptions of the thermodynamic equations, and in particular limits the heat capacity to being a constant. To demonstrate this, examine the definition for the chemical reaction equilibrium constant

$$
K_{e q}=\frac{k_{+}}{k_{-}}=e^{-\frac{\Delta G_{r x n}}{R T}}
$$

where $\Delta G_{r x n}$ is the change in Gibbs free energy of the reaction ( $\left.\mathrm{cal} \mathrm{mol}^{-1}\right)$. In addition, the GibbsHelmholtz equation and definition of the heat capacity as it relates to the enthalpy are defined as

$$
\frac{\partial\left(\frac{G}{T}\right)}{\partial T}=-\frac{H}{T^{2}},
$$

and

$$
\frac{\partial H}{\partial T}=C_{p}
$$

where $H$ is the enthalpy $\left(\mathrm{cal} \mathrm{mol}^{-1}\right.$ ) and $C_{p}$ is the constant pressure heat capacity (cal mol ${ }^{-1} \mathrm{~K}^{-1}$ ). By substituting the Arrhenius equation into these equations, the resulting heat capacity is equal to the gas constant $R$ times the difference between the backward and forward exponents of the temperature in the Arrhenius equations ( $\left.n_{\text {reverse }}-n_{\text {forward }}\right)$, a constant with respect to temperature. The use of the NASA polynomials (or the equivalent Shomate equation) for the thermodynamic properties does not match this assumption for the kinetics. At low temperatures this is generally not an issue, but at elevated temperatures this can cause inconsistencies in the established driving force for the kinetics and may lead to numerical errors that can slow down the code. This known issue will be examined in future work. For this current report, we continue with both the NASA polynomials and the Arrhenius assumption, and we 
refit those equations presented by Finko [50] that are not in the Arrhenius form for use with the code. The kinetic equations, their original rate constants, and their refitted values appear in APPENDIX B.

In addition to the thermodynamic/kinetic descriptions, the debris code uses three approximations for estimating the vapor pressure of the condensed phase to approximate its equilibrium with the gas. The user can provide a vapor curve in functional form, but no data are available for uranium oxides for the temperatures of interest. Alternatively, the codes employ the Clausius-Clapeyron equation, a common approximation for relating the vapor pressure to the thermodynamic properties of the material [51]. This approximation assumes an ideal gas phase with a significantly larger molar volume than the corresponding condensed phase. The vapor pressure at a given temperature is then related to the heat of vaporization for the material which, through the Gibbs-Helmholtz equation above, is related to the total free energy of the condensed phase, including the surface energy. For our current scenario, we are assuming this approximation to be valid, although because the gas is reactive and direct volatility is difficult to assess, we have treated the relationship as only describing the reaction between gas phase $\mathrm{UO}_{2}$ and condensed, liquid $\mathrm{UO}_{2}$, with all other reacting species being created or removed through gas phase reactions. Thus, as treated in the current iteration of the code, $\mathrm{UO}_{2}$ is the only species allowed to condense. The heat of vaporization is calculated from the reference thermodynamic values at the reference normal boiling point [46] and is treated as constant for the calculation.

The second approximation, the Eötvös rule [52], estimates the surface energy of a condensed phase as a linear function of temperature and an inverse function of its molar volume to a power of two-thirds:

$$
\gamma=q V^{-\frac{2}{3}}\left(T_{c}-T\right)
$$

where $\gamma$ is the surface energy $\left(\mathrm{J} \mathrm{m}^{-2}\right), q$ is a constant $\left(2.1 \times 10^{-7} \mathrm{~J} \mathrm{~K}^{-1} \mathrm{~mol}^{-2 / 3}\right), V$ is the molar volume $\left(\mathrm{m}^{3}\right.$ $\mathrm{mol}^{-1}$ ), and $T_{c}$ is the critical temperature $(\mathrm{K})$. The third, related approximation is the Guldberg approximation [53], which assumes that the value of the critical temperature is approximately 1.5 times the normal boiling point. This approximation is used directly in the Eötvös rule to replace the critical temperature with the normal boiling point.

For $\mathrm{UO}_{2}$, these approximations were compared to the surface energy, molar density, and phase change behavior relationships reviewed by Fink [49]. Although we found that the Eötvös rule could replicate the surface tension relationship identified by Fink, it required that the boiling point be set to a temperature of $3,880 \mathrm{~K}$ (approximately $65^{\circ}$ higher than the estimated point reported by Fink at 3,815.1 $\mathrm{K}$ as calculated from total vapor pressure relationships) and a liquid density calculated at 4,747.6 K based on Fink's reported density relationships. These inconsistencies generally suggest that the Guldberg approximation, which was originally developed for organic compounds, is likely not appropriate for these inorganic molecules and that complicated behavior can arise from multiple gas phase species being produced above a pure condensed phase. For the purposes of this preliminary effort, however, the effect of the surface tension on the particle energetics was the most desirable property, so we set the physical properties to those that would best replicate the surface energy, as described above.

With this framework in place, we have performed a basic simulation to test the performance of the code. An injection of $331.8 \mathrm{~kg}$ of $\mathrm{O}_{2}$ and $2,467.8 \mathrm{~kg} \mathrm{U}$ into a $8,508.06 \mathrm{~m}^{3}$ space $\left(1.2187 \mathrm{~mol} / \mathrm{m}^{3}\right.$ of both $\mathrm{O}_{2}$ and $\mathrm{U})$ at $5,000 \mathrm{~K}$, representing an initial vaporization of $\mathrm{UO}_{2}$ at atmospheric pressure, was simulated and allowed to react according to the reaction scheme as the system cooled according to the code's internal modified Hillendahl thermal profile [9]. Results for the gas phase speciation are presented in Figure 7 and for the temperature profile and particulate count in Figure 8. As illustrated by the simulation, atomic oxygen and uranium dominate the gas phase chemistry, and the system lacks sufficient density for significant recombination at these concentrations. In a real system, the expectation would be that metallic 
uranium would also condense; however, this was suppressed in this simulation to perform checks on the stoichiometry for this complex reaction scheme. Importantly, a molar ratio of 2:1 oxygen to uranium ratio was maintained in the gas phase throughout the simulation, as expected when starting with a 2:1 ratio and when $\mathrm{UO}_{2}$ is the only species allowed to condense. As the system cools, $\mathrm{UO}_{2}$ rapidly grows in the gas phase until the simulation reaches about 1.5 seconds. At that point, the initial nucleation of the condensed phase occurs in a complex relationship with the gas phase species. A second burst of nucleation occurs at approximately 4 seconds as the continuous production of $\mathrm{UO}_{2}$ and decreasing temperature bring the vapor pressure of this species above the required level of supersaturation. The numerical noise between times 3 and 4 seconds in the gaseous concentration of $\mathrm{UO}_{2}$ appears to be from the competition between the nucleation of new particles and the formation of new gaseous $\mathrm{UO}_{2}$ from chemical reactions during the period of rapid change, indicating that the time steps may not be sufficiently small in this region to capture the behavior.

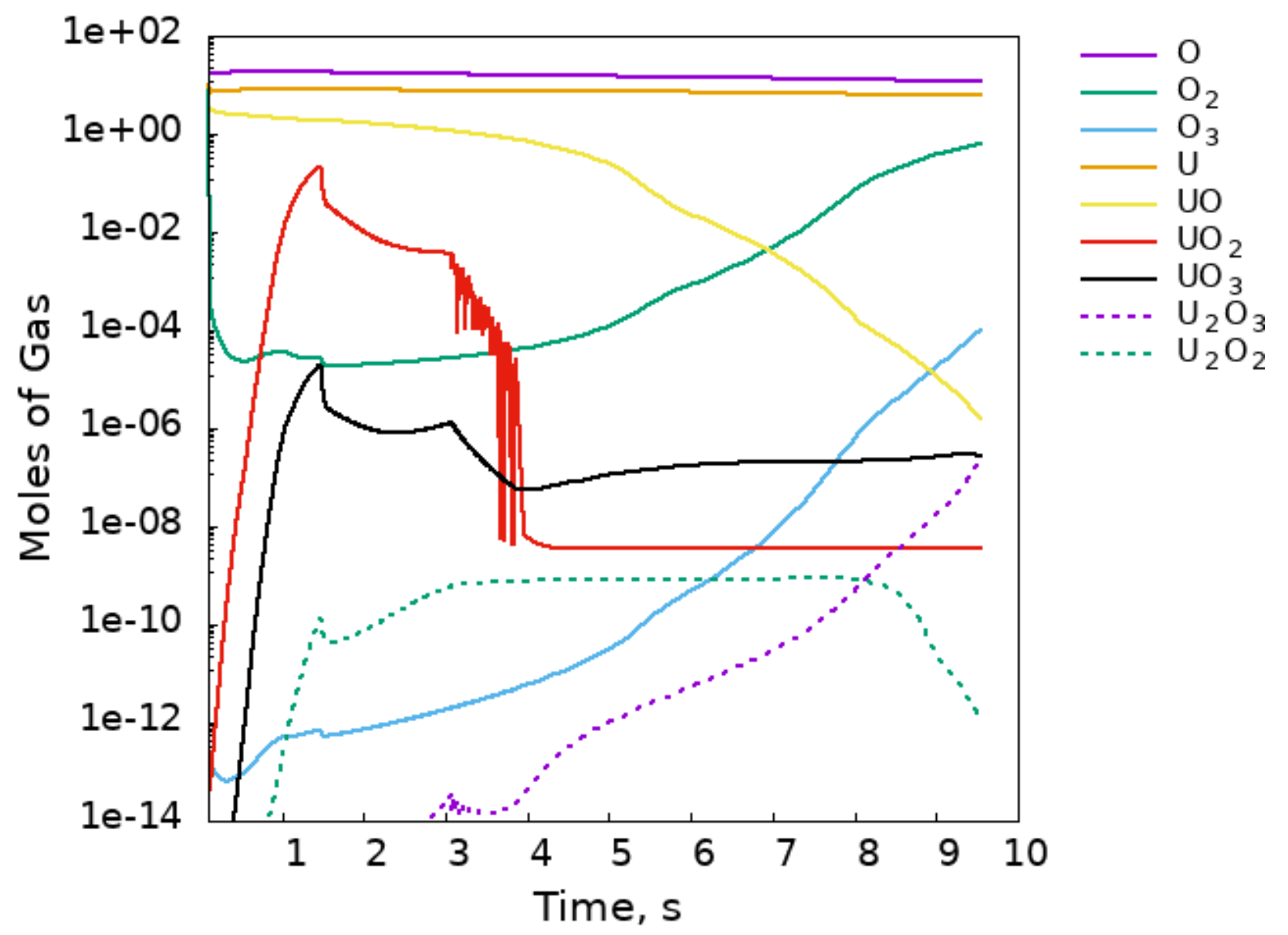

Figure 7. Chemical evolution of species with time as the test system evolved. 


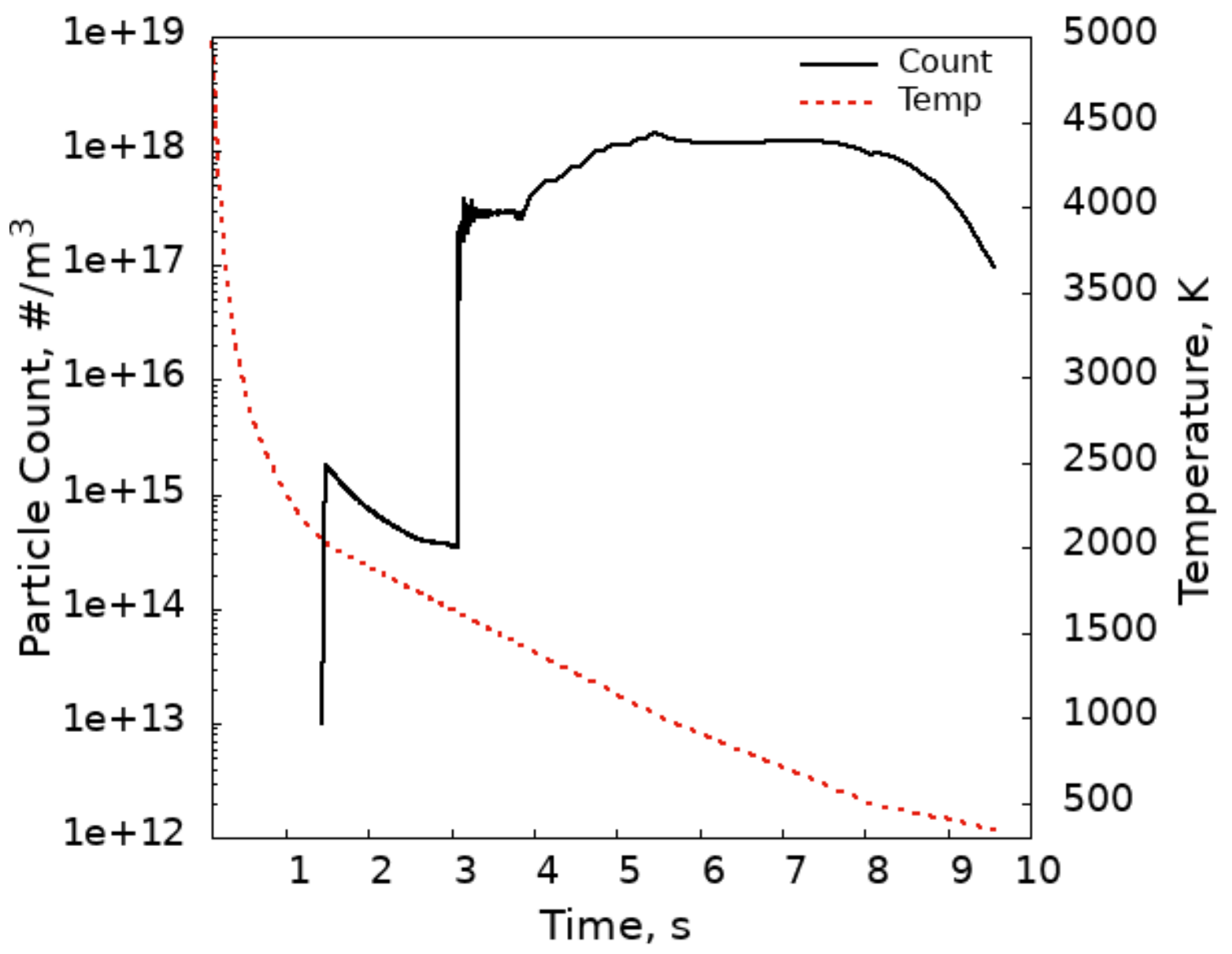

Figure 8. Temperature history and particle count per cubic meter for the simulated chemistry.

In this intentionally artificial simulation, it is not useful to draw conclusions about the meaning of these results other than that complex relationships exist in the uranium-oxide system and that careful efforts are required to evaluate the system appropriately. This initial effort was designed to examine how the research code addresses the physical behavior of complex chemical systems, ensures atomic balance is maintained, and determines whether physical behaviors are addressed consistently. As this work continues, we will introduce more realistic simulations including additional efforts to incorporate condensation of other species, and we will evaluate and make appropriate modifications to the code to treat the chemical reaction rates at the appropriate time step. Our focus will be to maintain consistency between physical properties as we integrate the continuous description of debris formation with the solid phase chemical behavior outlined by the atomic simulations.

\section{SUMMARY AND FUTURE WORK}

The investigation of nuclear fallout debris formation by molecular dynamics or Monte Carlo techniques requires the use of accurate classical potentials for uranium-oxygen systems. Of the 14 potentials reviewed, the EAM Cooper-14 potential by Cooper, Rushton, and Grimes [30] appears to reproduce the bulk properties of solid $\mathrm{UO}_{2}$ the most accurately. However, additional research is needed to validate its predictive performance for other stoichiometries and the liquid and gas phases. The COMB Li-19 potential also appears to perform reasonably well compared to older potentials such as Yakub-09 and has the added benefit of being tested against many uranium oxide phases $\left(\mathrm{UO}, \mathrm{UO}_{2}, \mathrm{UO}_{3}, \mathrm{U}_{3} \mathrm{O}_{8}\right.$, etc.). 
Unfortunately, the COMB potential is significantly more expensive computationally than EAM potentials, and there are very few peer-reviewed articles validating its predictive performance because it is relatively new. Any predictions derived from classical MD involving phase transitions of uraniumoxygen systems will require extensive validation, as most classical uranium-oxygen potentials are solely fit to reproduce the fluorite $\mathrm{UO}_{2}$ structure. Because of the expensive and hazardous nature of experiments involving radioactive material, ab initio computational modeling methods such as DFT will inevitably play a large role in this validation process.

DFT, MD, and MC models can be combined to study particle nucleation from the gas phase. In the absence of sufficient experimental data, ab initio calculations like DFT are required at two stages in a nucleation simulation workflow. The first is in the initial parameterization of the empirical force fields that will be used in MD or MC models. The chemical and physical properties of a given molecule or material are calculated with DFT, and these values are used in the fitting of new force fields. The accuracy of force fields is then reported relative to how well they reproduce the original fitting values, or new properties are calculated with MD and DFT and the results are compared. Figure 4 and Figure 5 illustrate this standard practice of evaluating interatomic potentials by comparison to both experimental and DFT-determined values. Finally, the simulation results from the large-scale dynamic runs can be validated against smaller DFT calculations. MD and MC simulations generate static snapshots of the system configuration, which can be written at each new step. Practically speaking, these snapshots are generated at given intervals, rather than each step, but they provide an atomic configuration that can serve as the input to DFT. Carefully selected small-scale validation runs can be performed, and the results can be compared to either QMD (or ab initio molecular dynamics, where the empirical potentials are replaced with DFT calculations of the forces acting on the atoms) or static DFT. Acceptable performance of the empirical potentials in these validation runs provides confidence in the results of more complex simulations of large systems.

Continual developments in HPC resources allow access to larger system sizes and longer length scales. To take full advantage of leadership class advancements in HPC, code development must scale with HPC improvements. Unfortunately, heavy element systems are rarely a priority for developers. Nucleation models at the level of QMD are presently beyond the scope of even leadership class HPC resources. Larger systems and longer length scales than ever before are achievable on these resources using classical molecular dynamics. Modern exascale architecture and supported code development, however, may make fully ab initio simulations of gas phase nucleation events possible.

The next steps in this project will focus on the use of the classical potentials identified to compute properties of the molecular cluster populations for uranium-oxygen systems in the gas phase at different thermodynamic conditions. These results will be employed in the development of more accurate functional descriptions that can be incorporated within the formulation of the continuum scale calculations. Code development at the continuum scale for accurate description of the gas phase environment with time, which can both serve as a platform for implementation of DFT and MD/MCderived properties at larger scales and can provide accurate starting conditions for these atom-level simulations, will continue. These approaches will be later extended to other oxide systems related to the mass chains most commonly used as part of post- detonation forensic analysis.

\section{ACKNOWLEDGMENTS}

This work was funded by the Office of Nuclear Detonation Detection-Forensics Program within the US Department of Energy's National Nuclear Security Administration as part of the Rapid Response Research Venture. 


\section{REFERENCES}

[1] A. J. Fahey, C. J. Zeissler, D. E. Newbury, J. Davis, and R. M. Lindstrom, "Postdetonation nuclear debris for attribution," Proc. Natl. Acad. Sci. USA, vol. 107, no. 47, pp. 20207-20212, 2010, doi: 10.1073/pnas.1010631107.

[2] E. C. Freiling, "Radionuclide fractionation in bomb debris," Science, vol. 133, no. 3469, pp. 19911998, 1961, doi: 10.1126/science.133.3469.1991.

[3] P. Moresco, Chemical Fractionation in Systems Condensing from the Gas Phase, 2021.ORNL/TM-2020/1767, Oak Ridge National Laboratory, Oak Ridge, TN.

[4] Y. B. Zel'dovich and Y. P. Raizer, Physics of shock waves and high-temperature hydrodynamic phenomena. Mineola: Dover Publications, 2002.

[5] W. W. Kellogg, R. R. Rapp, and S. M. Greenfield, "Close-in fallout," J. Meteorol., vol. 14, no. 1, pp. 1-8, 1957.

[6] G. R. Eppich, K. B. Knight, T. W. Jacomb-Hood, G. D. Spriggs, and I. D. Hutcheon, "Constraints on fallout melt glass formation from a near-surface nuclear test," J. Radioanal. Nucl. Chem., vol. 302, no. 1, pp. 593-609, 2014, doi: 10.1007/s10967-014-3293-9.

[7] S. S. Harilal E. J. Katuz, B. E. Bernacki, M. C. Phillips, P.J. Skrodzki, M. Burger, and I. Jovanovic, "Physical conditions for UO formation in laser-produced uranium plumes," Phys. Chem. Chem. Phys., vol. 21, no. 29, pp. 16161-16169, 2019, doi: 10.1039/c9cp02250c.

[8] B. Koroglu, M. Mehl, M. R. Armstrong, J. C. Crowhurst, D. G. Weisz, J. M. Zaug, Z. Dai, H. B. Radousky, A. Chernov, E. Ramon, et al., "Plasma flow reactor for steady state monitoring of physical and chemical processes at high temperatures," Rev. Sci. Instrum., vol. 88, no. 9, 2017, doi: $10.1063 / 1.5001346$.

[9] P. Moresco, "Description of nucleation, growth, and coagulation processes in the modeling of debris formation after a nuclear burst," 2021. doi: ORNL/TM-2020/1694.

[10] R. Zhang, A. Khalizov, L. Wang, M. Hu, and W. Xu, "Nucleation and growth of nanoparticles in the atmosphere," Chem. Rev., vol. 112, no. 3, pp. 1957-2011, 2012, doi: 10.1021/cr2001756.

[11] J. H. Seinfeld and S. N. Pandis, Atmospheric Chemistry and Physics: From Air Pollution to Climate Change, 3rd ed. Wiley, 2016.

[12] C. Hung, M. J. Krasnopoler, and J. L. Katz, "Condensation of a supersaturated vapor. VIII. The homogeneous nucleation of n-nonane," J. Chem. Phys., vol. 90, no. 3, p. 1856, Jun. 1998, doi: $10.1063 / 1.456027$.

[13] J. Feder, K. C. Russell, J. Lothe, and G. M. Pound, "Homogeneous nucleation and growth of droplets in vapours," Adv. Phys., vol. 15, no. 57, pp. 111-178, Jan. 1966, doi: $10.1080 / 00018736600101264$

[14] D. J. McGinty, "Molecular dynamics studies of the properties of small clusters of argon atoms," $J$. Chem. Phys., vol. 58, pp. 4733-4742, 1973, doi: 10.1063/1.1679052.

[15] J. K. Lee, J. A. Barker, and F. F. Abraham, "Theory and Monte Carlo simulation of physical clusters in the imperfect vapor," J. Chem. Phys., vol. 58, no. 8, pp. 3166-3180, Apr. 1973, doi: 10.1063/1.1679638.

[16] R. Angélil, J. Diemand, K. K. Tanaka, and H. Tanaka, "Homogeneous SPC/E water nucleation in large molecular dynamics simulations," J. Chem. Phys., vol. 143, no. 6, 2015, doi:

$10.1063 / 1.4928055$. 
[17] S. M. Kathmann, G. K. Schenter, B. C. Garrett, B. Chen, and J. I. Siepmann, "Thermodynamics and kinetics of nanoclusters controlling gas-to-particle nucleation," J. Phys. Chem. C, vol. 113, no. 24, pp. 10354-10370, 2009, doi: 10.1021/jp8092226.

[18] M. W. D. Cooper et al., "Development of Xe and $\mathrm{Kr}$ empirical potentials for $\mathrm{CeO}_{2}, \mathrm{ThO}_{2}, \mathrm{UO}_{2}$ and $\mathrm{PuO}_{2}$, combining DFT with high temperature MD," J. Phys. Condens. Matter, vol. 28, no. 40, 2016.

[19] J. R. Walker and C. R. A. Catlow, "Structural and dynamic properties of $\mathrm{UO}_{2}$ at high temperatures," J. Phys. C Solid State Phys., vol. 14, no. 32, p. L979, Nov. 1981, doi: 10.1088/0022-3719/14/32/004.

[20] K. Yamada, K. Kurosaki, M. Uno, and S. Yamanaka, "Evaluation of thermal properties of uranium dioxide by molecular dynamics," J. Alloys Compd., vol. 307, no. 1-2, pp. 10-16, Jul. 2000, doi: 10.1016/S0925-8388(00)00806-9.

[21] C. B. Basak, A. K. Sengupta, and H. S. Kamath, "Classical molecular dynamics simulation of $\mathrm{UO}_{2}$ to predict thermophysical properties," J. Alloys Compd., vol. 360, no. 1-2, pp. 210-216, Oct. 2003, doi: 10.1016/S0925-8388(03)00350-5.

[22] G. Busker, R. W. Grimes, and M. R. Bradford, "The solution and diffusion of ruthenium in $\mathrm{UO}_{2 \pm x}$, , J. Nucl. Mater., vol. 312, no. 2-3, pp. 156-162, Feb. 2003, doi: 10.1016/S00223115(02)01591-X.

[23] N. D. Morelon, D. Ghaleb, J. M. Delaye, and L. Van Brutzel, "A new empirical potential for simulating the formation of defects and their mobility in uranium dioxide," Philos. Mag., vol. 83, no. 13, pp. 1533-1555, Jan. 2003, doi: 10.1080/1478643031000091454.

[24] T. Arima, S. Yamasaki, Y. Inagaki, and K. Idemitsu, "Evaluation of thermal properties of $\mathrm{UO}_{2}$ and $\mathrm{PuO}_{2}$ by equilibrium molecular dynamics simulations from 300 to 2000K," J. Alloys Compd., vol. 400, no. 1-2, pp. 43-50, Sep. 2005, doi: 10.1016/j.jallcom.2005.04.003.

[25] A. Boyarchenkov, S. Potashnikov, K. Nekrasov, and A. Y. Kupryazhkin, "Molecular dynamics fitting of interatomic pair potentials in uranium dioxide by thermal expansion," Int. Sci. J. Altern. Energy Ecol., vol. 8, pp. 43-52, 2007, [Online]. Available:

https://www.researchgate.net/publication/319269267_Molecular_dynamics_fitting_of_interatomic _pair_potentials_in_uranium_dioxide_by_thermal_expansion.

[26] A. Y. Kupryazhkin, A. N. Zhiganov, D. V. Risovany, K. A. Nekrassov, V. D. Risovany, and V. N. Golovanov, "Simulation of diffusion of oxygen and uranium in uranium dioxide nanocrystals," $J$. Nucl. Mater., vol. 372, no. 2-3, pp. 233-238, Jan. 2008, doi: 10.1016/j.jnucmat.2007.03.176.

[27] P. Goel, N. Choudhury, and S. L. Chaplot, "Atomistic modeling of the vibrational and thermodynamic properties of uranium dioxide, $\mathrm{UO}_{2}$," J. Nucl. Mater., vol. 377, no. 3, pp. 438443, Jul. 2008, doi: 10.1016/j.jnucmat.2008.03.020.

[28] E. Yakub, C. Ronchi, and D. Staicu, "Computer simulation of defects formation and equilibrium in non-stoichiometric uranium dioxide," J. Nucl. Mater., vol. 389, no. 1, pp. 119-126, May 2009, doi: 10.1016/j.jnucmat.2009.01.029.

[29] P. Tiwary, A. Van De Walle, B. Jeon, and N. Grønbech-Jensen, "Interatomic potentials for mixed oxide and advanced nuclear fuels," Phys. Rev. B, vol. 83, no. 9, pp. 1-6, 2011, doi: 10.1103/PhysRevB.83.094104.

[30] M. W. D. Cooper, M. J. D. Rushton, and R. W. Grimes, "A many-body potential approach to modelling the thermomechanical properties of actinide oxides," J. Phys. Condens. Matter, vol. 26, no. 10, p. 105401, Mar. 2014, doi: 10.1088/0953-8984/26/10/105401. 
[31] Y. Li, "A universal COMB potential for the whole composition range of the uranium oxygen system,” J. Nucl. Mater., vol. 513, pp. 102-119, Jan. 2019, doi: 10.1016/j.jnucmat.2018.10.043.

[32] D. Mbongo, R. Tétot, R. Ducher, R. Dubourg, and N. Salles, "Improved SMTB-Q model applied to oxygen migration and pressure phase transitions in $\mathrm{UO}_{2}$, , J. Phys. Condens. Matter, vol. 32, no. 9, p. 095701, Feb. 2020, doi: 10.1088/1361-648X/ab559d.

[33] S. I. Potashnikov, A. S. Boyarchenkov, K. A. Nekrasov, and A. Y. Kupryazhkin, "High-precision molecular dynamics simulation of $\mathrm{UO}_{2}-\mathrm{PuO}_{2}$ : Pair potentials comparison in $\mathrm{UO}_{2}$, , J. Nucl. Mater., vol. 419, no. 1-3, pp. 217-225, 2011, doi: 10.1016/j.jnucmat.2011.08.033.

[34] K. Govers, S. Lemehov, M. Hou, and M. Verwerft, "Comparison of interatomic potentials for $\mathrm{UO}_{2}$. Part I: Static calculations,” J. Nucl. Mater., vol. 366, no. 1-2, pp. 161-177, Jun. 2007, doi: 10.1016/j.jnucmat.2006.12.070.

[35] K. Govers, S. Lemehov, M. Hou, and M. Verwerft, "Comparison of interatomic potentials for $\mathrm{UO}_{2}$. Part II: Molecular dynamics simulations,” J. Nucl. Mater., vol. 376, no. 1, pp. 66-77, May 2008, doi: 10.1016/j.jnucmat.2008.01.023.

[36] H. Balboa, L. Van Brutzel, A. Chartier, and Y. Le Bouar, "Assessment of empirical potential for MOX nuclear fuels and thermomechanical properties," J. Nucl. Mater., vol. 495, pp. 67-77, Nov. 2017, doi: 10.1016/j.jnucmat.2017.07.067.

[37] Y. Ida, "Interionic repulsive force and compressibility of ions," Phys. Earth Planet. Inter., vol. 13, no. 2, pp. 97-104, Jan. 1976, doi: 10.1016/0031-9201(76)90074-1.

[38] E. Yakub, C. Ronchi, and D. Staicu, "Molecular dynamics simulation of premelting and melting phase transitions in stoichiometric uranium dioxide," J. Chem. Phys., vol. 127, no. 9, 2007, doi: 10.1063/1.2764484.

[39] M. W. D. Cooper et al., "Development of $\mathrm{Xe}$ and $\mathrm{Kr}$ empirical potentials for $\mathrm{CeO}_{2}, \mathrm{ThO}_{2}, \mathrm{UO}_{2}$ and $\mathrm{PuO}_{2}$, combining DFT with high temperature MD," J. Phys. Condens. Matter, vol. 28, no. 40, p. 405401, Oct. 2016, doi: 10.1088/0953-8984/28/40/405401.

[40] X. Y. Liu et al., "Molecular dynamics simulation of thermal transport in $\mathrm{UO}_{2}$ containing uranium, oxygen, and fission-product defects," Phys. Rev. Appl., vol. 6, no. 4, p. 044015, Oct. 2016, doi: 10.1103/PhysRevApplied.6.044015.

[41] Y. Li, T. Liang, S. B. Sinnott, and S. R. Phillpot, "A charge-optimized many-body potential for the $\mathrm{U}-\mathrm{UO}_{2}-\mathrm{O}_{2}$ system," J. Phys. Condens. Matter, vol. 25, no. 50, p. 505401, Dec. 2013, doi: $10.1088 / 0953-8984 / 25 / 50 / 505401$.

[42] S. J. Plimpton and A. P. Thompson, "Computational aspects of many-body potentials," MRS Bull., vol. 37, no. 5, pp. 513-521, May 2012, doi: 10.1557/mrs.2012.96.

[43] C. W. Gear, "The automatic integration of ordinary differential equations," Commun. ACM, vol. 14, no. 3, pp. 176-179, Mar. 1971, doi: 10.1145/362566.362571.

[44] B. J. McBride and S. Gordon, "Computer Program for Calculation of Complex Chemical Equilibrium Compositions and Applications II. Users Manual and Program Description,” NASA Reference Publication 1311, 1996.

[45] J. D. Cox, CODATA key values for thermodynamics(QD504 .C62). New York: Hemisphere Pub. Corp., 1989.

[46] R. J. M. Konings et al., "The thermodynamic properties of the f-elements and their compounds: Part 2. The lanthanide and actinide oxides," J. Phys. Chem. Ref. Data, vol. 43, no. 1, 2014, doi: $10.1063 / 1.4825256$. 
[47] I. Grenthe et al., "Second update on the chemical thermodynamics of uranium, neptunium, plutonium, americium and technetium Chemical thermodynamics," Nuclear Energy Agency of the OECD (NEA), 2020.

[48] M. Guido and G. Balducci, "Identification and stability of $\mathrm{U}_{2} \mathrm{O}_{2}, \mathrm{U}_{2} \mathrm{O}_{3}$, and $\mathrm{U}_{2} \mathrm{O}_{4}$ gaseous oxides molecules," J. Chem. Phys., vol. 95, no. 7, pp. 5373-5376, Oct. 1991, doi: 10.1063/1.461652.

[49] J. K. Fink, “Thermophysical properties of uranium dioxide," J. Nucl. Mater., vol. 279, no. 1, pp. 1-18, 2000, doi: 10.1016/S0022-3115(99)00273-1.

[50] M. S. Finko et al., "A model of early formation of uranium molecular oxides in laser-ablated plasmas," J. Phys. D. Appl. Phys., vol. 50, no. 48, p. aa92f5, 2017, doi: 10.1088/13616463/aa92f5.

[51] H. B. Callen, Thermodynamics and an Introduction to Thermostatistics, 2nd ed. New York: John Wiley \& Sons, Inc., 1985.

[52] R. Eötvös, "Ueber den zusammenhang der oberflächenspannung der flüssigkeiten mit ihrem Molecularvolumen," Ann. der Phys. und Chemie, vol. 263, no. 3, pp. 448-459, 1886, doi: 10.1002/andp.18862630309.

[53] C. M. Guldberg, "Über die gesetze der molekularvolumina und der siedepunkte," Zeitschrift für Phys. Chemie, vol. 5U, no. 1, pp. 374-382, Feb. 1890, doi: 10.1515/zpch-1890-0534. 


\section{APPENDIX A. Thermodynamic parameters for the U-O system}

Table A-1. Thermodynamic parameters used for determining heat capacity and enthalpy values for uranium oxide calculations. All energy units are in $\mathbf{J} / \mathbf{m o l}$, and temperature is in $\mathrm{K}$.

\begin{tabular}{|c|c|c|c|c|c|c|c|c|c|c|}
\hline Species & A1 & A2 & A3 & A4 & A5 & A6 & A7 & B1 & B2 & Ref \\
\hline $\mathrm{O}$ & -5338.320 & 108.457 & 2.2844 & $\begin{array}{r}1.9735 \\
\times 10^{-4} \\
\end{array}$ & $\begin{array}{r}-9.027 \\
\times 10^{-8} \\
\end{array}$ & $\begin{array}{r}1.9787 \\
\times 10^{-11} \\
\end{array}$ & $\begin{array}{r}-1.4171 \\
\times 10^{-15} \\
\end{array}$ & 28644.56 & 6.6337 & $12^{*}$ \\
\hline $\mathrm{O}_{2}$ & 7230.544 & -73.629 & 3.4384 & $\begin{array}{r}1.0663 \\
\times 10^{-3} \\
\end{array}$ & $\begin{array}{r}-3.409 \\
\times 10^{-7}\end{array}$ & $\begin{array}{r}5.6370 \\
\times 10^{-11}\end{array}$ & $\begin{array}{r}-3.4089 \\
\times 10^{-15}\end{array}$ & -630.16 & 4.5629 & $12^{*}$ \\
\hline $\mathrm{O}_{3}$ & 58011.437 & $\begin{array}{r}-872.07 \\
7\end{array}$ & 6.9021 & $\begin{array}{r}8.3527 \\
\times 10^{-4} \\
\end{array}$ & \begin{tabular}{|c|}
-4.301 \\
$4 \times 10^{-7}$ \\
\end{tabular} & $\begin{array}{r}8.8007 \\
\times 10^{-11} \\
\end{array}$ & $\begin{array}{r}-6.1437 \\
\times 10^{-15} \\
\end{array}$ & 20223.34 & -13.4441 & $12^{*}$ \\
\hline $\begin{array}{l}\mathrm{U} \\
\mathrm{T}<4000 \mathrm{~K}\end{array}$ & 19302.795 & $\begin{array}{r}-401.46 \\
8\end{array}$ & 4.9996 & \begin{tabular}{|}
-4.455 \\
$3 \times 10^{-3}$
\end{tabular} & $\begin{array}{r}3.5729 \\
\times 10^{-6} \\
\end{array}$ & \begin{tabular}{|r|}
-8.685 \\
$4 \times 10^{-}$ \\
10
\end{tabular} & $\begin{array}{r}7.0418 \\
\times 10^{-14} \\
\end{array}$ & 65139.84 & -4.5234 & $3 *$ \\
\hline $\begin{array}{l}\mathrm{U} \\
\mathrm{T}>4000 \mathrm{~K}\end{array}$ & 0 & 0 & 6.6653 & 0 & 0 & 0 & 0 & 65139.84 & -21.4979 & 3* \\
\hline $\begin{array}{l}\mathrm{UO} \\
\mathrm{T}<1300 \mathrm{~K}\end{array}$ & -62007.938 & 0 & 4.6284 & $\begin{array}{r}3.9715 \\
\times 10^{-3} \\
\end{array}$ & $\begin{array}{r}-4.865 \\
5 \times 10^{-6} \\
\end{array}$ & $\begin{array}{r}1.7741 \\
\times 10^{-9} \\
\end{array}$ & 0 & 849.00 & 2.6235 & 4 \\
\hline $\begin{array}{l}\mathrm{UO} \\
\mathrm{T}>1300 \mathrm{~K}\end{array}$ & 301836.661 & 0 & 6.0199 & $\begin{array}{r}-2.178 \\
3 \times 10^{-3}\end{array}$ & $\begin{array}{r}1.4887 \\
\times 10^{-6} \\
\end{array}$ & $\begin{array}{r}-2.062 \\
0 \times 10^{-} \\
10\end{array}$ & 0 & 1277.1195 & -3.1701 & 4 \\
\hline \begin{tabular}{|l|}
$\mathrm{UO}_{2}$ \\
$\mathrm{~T}<900 \mathrm{~K}$ \\
\end{tabular} & -9002.999 & 0 & 5.3353 & $\begin{array}{r}4.5268 \\
\times 10^{-3} \\
\end{array}$ & \begin{tabular}{r|}
-2.785 \\
$1 \times 10^{-6}$ \\
\end{tabular} & $\begin{array}{r}6.6186 \\
\times 10^{-10} \\
\end{array}$ & 0 & -57379.76 & 1.6400 & 4 \\
\hline \begin{tabular}{|l|}
$\mathrm{UO}_{2}$ \\
$\mathrm{~T}>900 \mathrm{~K}$
\end{tabular} & -76009.755 & 0 & 7.1657 & $\begin{array}{r}6.4859 \\
\times 10^{-4} \\
\end{array}$ & $\begin{array}{r}1.1382 \\
\times 10^{-8} \\
\end{array}$ & $\begin{array}{r}-1.237 \\
3 \times 10^{-} \\
11\end{array}$ & 0 & -58099.92 & -8.3313 & 4 \\
\hline \begin{tabular}{|l|}
$\mathrm{UO}_{3}$ \\
$\mathrm{~T}<900 \mathrm{~K}$
\end{tabular} & -33604.078 & 0 & 5.6161 & $\begin{array}{r}1.1390 \\
\times 10^{-2} \\
\end{array}$ & $\begin{array}{r}-1.141 \\
7 \times 10^{-5} \\
\end{array}$ & $\begin{array}{r}4.1086 \\
\times 10^{-9} \\
\end{array}$ & 0 & -97822.46 & 2.2570 & 4 \\
\hline \begin{tabular}{l|}
$\mathrm{UO}_{3}$ \\
$\mathrm{~T}>900 \mathrm{~K}$
\end{tabular} & $\begin{array}{r}-310362.64 \\
1\end{array}$ & 0 & 9.8280 & $\begin{array}{r}2.4170 \\
\times 10^{-4} \\
\end{array}$ & $\begin{array}{r}-1.335 \\
7 \times \\
10-7 \\
\end{array}$ & $\begin{array}{r}2.6013 \\
\times 10^{-11} \\
\end{array}$ & 0 & -99477.83 & -20.1091 & 4 \\
\hline $\begin{array}{l}\mathrm{U}_{2} \mathrm{O}_{2} \\
\mathrm{~T}<1000 \mathrm{~K}\end{array}$ & 0 & 0 & 2.11 & 0.0407 & $\begin{array}{r}-7.59 \times \\
10^{-5} \\
\end{array}$ & $\begin{array}{r}6.36 \times \\
10^{-8} \\
\end{array}$ & \begin{tabular}{|r|}
$-2.00 \times$ \\
$10^{-11}$ \\
\end{tabular} & -59000.00 & 19.0000 & 7 \\
\hline $\begin{array}{l}\mathrm{U}_{2} \mathrm{O}_{2} \\
\mathrm{~T}>1000 \mathrm{~K}\end{array}$ & 0 & 0 & 11.2 & $\begin{array}{r}-1.240 \\
0 \times 10^{-3} \\
\end{array}$ & $\begin{array}{r}7.07 \times \\
10^{-7} \\
\end{array}$ & \begin{tabular}{|r|}
$-9.26 \times$ \\
$10^{-11}$ \\
\end{tabular} & $\begin{array}{r}2.91 \times \\
10^{-15} \\
\end{array}$ & -60700.00 & -23.9000 & 7 \\
\hline $\begin{array}{l}\mathrm{U}_{2} \mathrm{O}_{3} \\
\mathrm{~T}<1000 \mathrm{~K}\end{array}$ & 0 & 0 & 7.59 & 0.0178 & $\begin{array}{r}-2.38 \times \\
10^{-5} \\
\end{array}$ & $\begin{array}{r}1.55 \times \\
10^{-8} \\
\end{array}$ & $\begin{array}{r}-3.87 \times \\
10^{-12} \\
\end{array}$ & -106000.00 & -2.7700 & 7 \\
\hline $\begin{array}{l}\mathrm{U}_{2} \mathrm{O}_{3} \\
\mathrm{~T}>1000 \mathrm{~K}\end{array}$ & 0 & 0 & 12.7 & $\begin{array}{r}1.52 \times \\
10^{-4} \\
\end{array}$ & $\begin{array}{r}5.14 \times \\
10^{-7} \\
\end{array}$ & \begin{tabular}{|r|}
$-1.29 \times$ \\
$10^{-10}$ \\
\end{tabular} & $\begin{array}{c}8.5 \times \\
10^{-15}\end{array}$ & -107000.00 & -28.3000 & 7 \\
\hline
\end{tabular}

*Regressed fit from tabulated data.

The parameters relate to the following equations for the thermodynamic properties:

$$
\begin{gathered}
\frac{C_{p}}{R}=\frac{A_{1}}{T^{2}}+\frac{A_{2}}{T}+A_{3}+A_{4} T+A_{5} T^{2}+A_{6} T^{3}+A_{7} T^{4} \\
\frac{H}{R}=-\frac{A_{1}}{T^{2}}+\frac{A_{2} \ln (T)}{T}+A_{3}+\frac{1}{2} A_{4} T+\frac{1}{3} A_{5} T^{2}+\frac{1}{4} A_{6} T^{3}+\frac{1}{5} A_{7} T^{4}+\frac{B_{1}}{T} \\
\frac{G}{R T}=-\frac{A_{1}}{2 T^{2}}+\frac{A_{2}}{T}(1+\ln (T))+A_{3}(1-\ln (T))-\frac{1}{2} A_{4} T-\frac{1}{6} A_{5} T^{2}-\frac{1}{12} A_{6} T^{3}-\frac{1}{20} A_{7} T^{4}+\frac{B_{1}}{T}-B_{2}
\end{gathered}
$$





\section{APPENDIX B. Kinetic reaction coefficients for the U-O system}

Table B-1. Reactions used in the calculation of uranium oxide speciation and their reaction rate constants.

Original kinetic constants are as reported in Finko [50]. Arrhenius values are refit or scaled as required by the code to fit the Arrhenius form and place the reaction rate in a $\mathrm{mol} / \mathrm{m}^{3} / \mathrm{s}$ basis.

\begin{tabular}{|c|c|c|c|c|}
\hline \multirow{2}{*}{ Reaction } & \multirow{2}{*}{$\begin{array}{c}\text { Original reported reaction } \\
\text { constant (molecules } / \mathrm{cm}^{3} / \mathbf{s} \text { basis) }\end{array}$} & \multicolumn{3}{|c|}{ Arrhenius Values Used (mol/m $/ \mathrm{m}^{3} / \mathrm{s}$ basis) } \\
\hline & & $\mathbf{A}$ & $\mathbf{n}$ & E, cal $/ \mathbf{m o l}$ \\
\hline $\mathrm{O}+\mathrm{O}_{2} \rightarrow 3 \mathrm{O}$ & $\begin{array}{l}1.28 \times 10^{-} \\
7(1-\exp (-2240 / \mathrm{T}))^{*} \exp (-59380 / \mathrm{T})\end{array}$ & $3.18552 \times 10^{12}$ & -0.55137928 & 118000.18878 \\
\hline $\mathrm{O}+\mathrm{O}_{3} \rightarrow 2 \mathrm{O}_{2}$ & $1.81 \times 10^{-11} \exp (-2300 / \mathrm{T})$ & 10899820 & 0 & 4570.5698 \\
\hline $\mathrm{O}+\mathrm{O}_{3} \rightarrow \mathrm{O}_{2}+2 \mathrm{O}$ & $4.16 \times 10^{-9} \exp (-11430 / \mathrm{T})$ & $2.505152 \times 10^{9}$ & 0 & 22713.7447 \\
\hline $2 \mathrm{O}_{2} \rightarrow \mathrm{O}_{2}+2 \mathrm{O}$ & $\begin{array}{l}3.6 \times 10^{-} \\
8(1-\exp (-2240 / \mathrm{T}) * \exp (-59380 / \mathrm{T})\end{array}$ & $8.95953 \times 10^{11}$ & -0.55137928 & 118000.18878 \\
\hline $2 \mathrm{O}_{2} \rightarrow \mathrm{O}_{3}+\mathrm{O}$ & $2 \times 10^{-11} \exp (-49800 / \mathrm{T})$ & 12044000 & 0 & 98962.7721 \\
\hline $\mathrm{O}_{2}+\mathrm{O}_{3} \rightarrow 2 \mathrm{O}_{2}+\mathrm{O}$ & $2.51 \times 10^{-10} \exp (-11600 / \mathrm{T})$ & 151152200 & 0 & 23051.5694 \\
\hline $3 \mathrm{O} \rightarrow \mathrm{O}_{2}+\mathrm{O}$ & $1.44 \times 10^{-32}(300 / \mathrm{T})^{0.41}$ & 54133.20105 & -0.41 & 0 \\
\hline $2 \mathrm{O}+\mathrm{O}_{2} \rightarrow 2 \mathrm{O}_{2}$ & $4 \times 10^{-33}(300 / \mathrm{T})^{0.41}$ & 15037.00029 & -0.41 & 0 \\
\hline $2 \mathrm{O}+\mathrm{O}_{2} \rightarrow \mathrm{O}_{3}+\mathrm{O}$ & $1.1 \times 10^{-34} \exp (1060 / \mathrm{T})$ & 39.8909324 & 0 & -2106.4365 \\
\hline $\mathrm{O}+2 \mathrm{O}_{2} \rightarrow \mathrm{O}_{3}+\mathrm{O}_{2}$ & $7.6 \times 10^{-34}(300 / T)^{1.9}$ & 14022500.97 & -1.9 & 0 \\
\hline $\mathrm{U}+\mathrm{O}_{2} \rightarrow \mathrm{UO}+\mathrm{O}$ & $3.36 \times 10^{-12} \mathrm{~T}^{0.5} \exp (-5161.7 / \mathrm{T})$ & $2.023392 \times 10^{6}$ & 0.5 & 10257.3522 \\
\hline $\mathrm{UO}+\mathrm{O} \rightarrow \mathrm{U}+\mathrm{O}_{2}$ & $*$ & $4.02527 \times 10^{11}$ & -1.35072 & 74699.64508 \\
\hline $\mathrm{U}+\mathrm{O}_{2} \rightarrow \mathrm{UO}_{2}$ & $3.36 \times 10^{-12} \mathrm{~T}^{0.5} \exp (-12910 / \mathrm{T})$ & $2.023392 \times 10^{6}$ & 0.5 & 25654.8070 \\
\hline $\mathrm{UO}_{2} \rightarrow \mathrm{U}+\mathrm{O}_{2}$ & * & $8.31495 \times 10^{34}$ & -2.26154102 & 265764.2431 \\
\hline $\mathrm{UO}+\mathrm{O}_{2} \rightarrow \mathrm{UO}_{2}+\mathrm{O}$ & $3.8 \times 10^{-11} \mathrm{~T}^{0.17}$ & $2.28836 \times 10^{7}$ & 0.17 & 0 \\
\hline $\mathrm{UO}_{2}+\mathrm{O} \rightarrow \mathrm{UO}+\mathrm{O}_{2}$ & * & $6.26862 \times 10^{8}$ & -0.03328508 & 55863.814 \\
\hline $\mathrm{UO}_{2}+\mathrm{O}_{2} \rightarrow \mathrm{UO}_{3}+\mathrm{O}$ & $1.17 \times 10^{-11} \mathrm{~T}^{0.5} \exp (-8915.7 / \mathrm{T})$ & $7.04574 \times 10^{6}$ & 0.5 & 17717.317 \\
\hline $\mathrm{UO}_{3}+\mathrm{O} \rightarrow \mathrm{UO}_{2}+\mathrm{O}_{2}$ & * & $2.17388 \times 10^{6}$ & 0.738849462 & 37000.13632 \\
\hline $\mathrm{U}_{2} \mathrm{O}_{3} \rightarrow \mathrm{U}_{2} \mathrm{O}_{2}+\mathrm{O}$ & $3 \times 10^{15} \exp (-68148.6 / \mathrm{T})$ & $3.0 \times 10^{15}$ & 0 & 135425.1881 \\
\hline $\mathrm{U}_{2} \mathrm{O}_{2}+\mathrm{O} \rightarrow \mathrm{U}_{2} \mathrm{O}_{3}$ & * & $9.89725 \times 10^{-10}$ & 1.525006581 & -16568.8028 \\
\hline $\mathrm{U}_{2} \mathrm{O}_{3} \rightarrow \mathrm{UO}_{2}+\mathrm{UO}$ & $3 \times 10^{15} \exp (-46023.3 / \mathrm{T})$ & $3.0 \times 10^{15}$ & 0 & 91457.6978 \\
\hline $\mathrm{UO}_{2}+\mathrm{UO} \rightarrow \mathrm{U}_{2} \mathrm{O}_{3}$ & * & $8.29484 \times 10^{-9}$ & 0.78106738 & -7924.85596 \\
\hline $\mathrm{U}_{2} \mathrm{O}_{3} \rightarrow \mathrm{UO}_{3}+\mathrm{U}$ & $3 \times 10^{15} \exp (-64746 / \mathrm{T})$ & $3.0 \times 10^{15}$ & 0 & 128663.5269 \\
\hline $\mathrm{UO}_{3}+\mathrm{U} \rightarrow \mathrm{U}_{2} \mathrm{O}_{3}$ & * & $6.90033 \times 10^{-16}$ & 3.223456664 & -16488.945 \\
\hline $\mathrm{U}_{2} \mathrm{O}_{2} \rightarrow 2 \mathrm{UO}$ & $1 \times 10^{15} \exp (-60010.1 / \mathrm{T})$ & $1.0 \times 10^{15}$ & 0 & 119252.3263 \\
\hline $2 \mathrm{UO} \rightarrow \mathrm{U}_{2} \mathrm{O}_{2}$ & * & $7.56409 \times 10^{-7}$ & -0.18593972 & -3192.93665 \\
\hline $\mathrm{U}_{2} \mathrm{O}_{2} \rightarrow \mathrm{U}+\mathrm{UO}_{2}$ & $1 \times 10^{15} \exp (-61175.1 / \mathrm{T})$ & $1.0 \times 10^{15}$ & 0 & 121567.4192 \\
\hline $\mathrm{UO}_{2}+\mathrm{U} \rightarrow \mathrm{U}_{2} \mathrm{O}_{2}$ & * & $5.58678 \times 10^{-12}$ & 1.814316731 & -10066.7656 \\
\hline $\mathrm{UO}_{3} \rightarrow \mathrm{UO}+\mathrm{O}_{2}$ & $1 \times 10^{15} \exp (-90465.3 / \mathrm{T})$ & $1.0 \times 10^{15}$ & 0 & 179773.0294 \\
\hline $\mathrm{UO}+\mathrm{O}_{2} \rightarrow \mathrm{UO}_{3}$ & * & $2.92521 \times 10^{-7}$ & 0.319152276 & -14566.4894 \\
\hline $\mathrm{UO}_{3} \rightarrow \mathrm{UO}_{2}+\mathrm{O}$ & $1 \times 10^{15} \exp (-733300.3 / \mathrm{T})$ & $1.0 \times 10^{15}$ & 0 & 145662.6683 \\
\hline $\mathrm{UO}_{2}+\mathrm{O} \rightarrow \mathrm{UO}_{3}$ & * & $8.01317 \times 10^{-6}$ & 0.115867192 & 7186.963505 \\
\hline $\mathrm{UO}_{2} \rightarrow \mathrm{UO}+\mathrm{O}$ & $1 \times 10^{15} \exp (-93229.8 / \mathrm{T})$ & $1.0 \times 10^{15}$ & 0 & 185266.6556 \\
\hline $\mathrm{UO}+\mathrm{O} \rightarrow \mathrm{UO}_{2}$ & * & $9.02536 \times 10^{-8}$ & 0.557999054 & 10209.95609 \\
\hline
\end{tabular}

*Reverse reactions for uranium species are not directly reported by Finko [50]. Instead, the reverse rate constants are calculated from the thermodynamic equilibrium constant, as described in Section 3, Equation (14). 


